\title{
Ventricular endoscopy in the pediatric population: review of indications
}

\author{
Omar Choudhri • Abdullah H. Feroze • Jay Nathan • \\ Samuel Cheshier • Raphael Guzman
}

Received: 11 July 2014 / Accepted: 14 July 2014 / Published online: 1 August 2014

(C) Springer-Verlag Berlin Heidelberg 2014

\begin{abstract}
Introduction Neuroendoscopy has greatly impacted pediatric neurosurgery over the past few decades. Improved optics and microsurgical tools have allowed neuroendoscopes to be used for a multitude of neurosurgical procedures.

Discussion In this review article, we present the breadth of intraventricular neuroendoscopic procedures for the treatment of conditions ranging from hydrocephalus and brain tumors to congenital cysts and other pathologies. We critically discuss treatment indications and reported success rates for neuroendoscopic procedures. We also present novel approaches, technical nuances, and variations from recently published literature and as practiced in the authors' institution.
\end{abstract}

Keywords Intraventricular $\cdot$ Endoscopy $\cdot$ Third ventriculostomy $\cdot$ Hydrocephalus $\cdot$ Catheter

\section{Introduction}

Following the development of the first modern endoscope by Max Nitze in 1879, ventricular neuroendoscopy was introduced

Omar Choudhri and Abdullah H. Feroze contributed equally to this work.

O. Choudhri $(\bowtie) \cdot$ A. H. Feroze $\cdot$ S. Cheshier $\cdot$ R. Guzman

Division of Pediatric Neurosurgery, Department of Neurosurgery, Lucile Packard Children's Hospital, Stanford University School of Medicine, 300 Pasteur Drive MC5327, Stanford, CA, USA

e-mail: omarc@stanford.edu

\section{R. Guzman}

Division of Pediatric Neurosurgery, Department of Neurosurgery, University Children's Hospital Basel, University of Basel, Basel, Switzerland

J. Nathan

Department of Neurosurgery, University of Michigan, Ann Arbor, MI, USA in 1910 when the urologist L'Espinasse first placed a rigid cystoscope within the intraventricular space to coagulate the choroid plexus of two patients with hydrocephalus [1,2]. Dandy subsequently performed the first third ventriculostomy and choroid plexectomy in 1922 [3]. Since then, with the advent of improved optics and endoscope technology, neuroendoscopes have become the cornerstone of minimally invasive neurosurgery, employed in a number of various procedures as primary or adjunctive means to traditional microsurgical approaches. Endoscopes provide the advantage of excellent visualization and illumination at angles not necessarily available using the surgical microscope. This allows the neurosurgeon to navigate around structures that would otherwise be hidden from the field of view in a routine craniotomy [4]. The cerebrospinal fluid (CSF) space is transparent and allows excellent visualization of deep brain structures and access to areas that otherwise would require wider craniotomies and complex skull base approaches.

With a rich history of major advances and creative approaches over the past century, neuroendoscopy continues to evolve as a treatment for many well-known neurosurgical pathologies [5]. Hydrocephalus is the most common neurosurgical pathology now treated by such methods. Pediatric neurosurgeons frequently employ neuroendoscopes to treat hydrocephalus by procedures such as endoscopic third ventriculostomy (ETV), choroid plexus ablation, cyst fenestration, and endoscopic placement of catheters. Intraventricular and paraventricular endoscopy in pediatric and adult patients is associated with improved outcomes, shorter operating times, and the decreased need for extensive craniotomies typically associated with greater morbidity. Furthermore, neuroendoscopic techniques permit smaller incisions, limit the need for brain retraction, decrease patient discomfort, and improve cosmetic results in pediatric patients [6]. Along with such practice shifts comes the increased emphasis on high-fidelity virtual training, given ventricular endoscopy's steep learning curve [7-10]. 
This review highlights the most common pediatric indications for intraventricular endoscopy and summarizes lessons learned through a detailed literature review as well as experiences at our institution. This review specifically covers ETV, endoscopic placement of ventricular catheters, intraventricular cyst fenestration and decompression (including arachnoid cysts), and intraventricular tumor biopsy and resection. We also critically review treatment indications for asymptomatic lesions and reported treatment success rates.

\section{Endoscopic third ventriculostomy}

Now a mainstay treatment for occlusive hydrocephalus, ETV has a long history of development and application to a variety of pathologies in pediatric neurosurgery. Most notably, ETV is the most widely performed and reported neuroendoscopic procedure for the treatment of obstructive hydrocephalus. ETV in pediatric patients dates back to 1923 when Mixter first used the procedure to treat a 9-month-old girl with hydrocephalus [11]. After decades of subpar outcomes, largely the result of poor instrumentation design and limited technology, ETV has surged in popularity in the last 30 years due in large part to critical improvements in lenses, instrumentation, and computing power. Since the first modern reports by Vries in 1978 on the use of fiber-optic endoscopy to perform ETV for hydrocephalus, numerous technical advances have made ETV progressively safer and more effective [12-14], resulting in increased clinical applications as detailed below.

\section{Indications}

Applying ETV to the correct clinical indication is the single greatest factor influencing its success in bringing relief to the pediatric patient. While ETV is applicable to both communicating and non-communicating hydrocephalus, ideal candidates are those with an obstructive etiology due to a variety of possible causes, including primary congenital anomalies such as aqueductal stenosis, myelomeningocele, and idiopathic causes [15-17]; obstruction secondary to pineal region tumors for which ETV and biopsy may be coupled [18-20]; aqueductal stenosis secondary to tectal gliomas [21]; and giant retrocerebellar cysts [22]. Some have found ETV to be effective in managing hydrocephalus in children with posterior fossa tumors prior to tumor resection [23, 24]. ETV also provides great utility in managing patients with obstructive hydrocephalus previously treated by ventriculoperitoneal shunting who present with shunt failure secondary to obstruction, infection, abdominal CSF pseudocyst, or other complications $[25,26]$. In cases where shunting can give rise to slitventricle syndrome, ETV has also been proven effective in assessing brain compliance. Specifically, if the brain is sufficiently compliant, the existing shunt is removed and ETV is performed during the same operation [27]. Such indications have made ETV a very valuable tool.

Operative technique

The operative technique for endoscopic third ventriculostomies has been extensively documented [28]. In our experience, use of a classical right frontal burr hole is typically employed. Access to the frontal horn of the lateral ventricle is subsequently achieved using an Elsberg cannula followed by insertion of a 12- or 14-French peel-away sheath. A 0-degree endoscope is passed through the peel-away sheet under constant irrigation with physiologic saline at body temperature. The tip of the balloon catheter or the stiff end of a vascular guide wire is used to perforate the floor of the third ventricle in the area of the tuber cinereum. Fogarty balloons or NeuroBalloons (Integra Life Science) are used to perform the ventriculostomy [29] (Fig. 1). Based on our practice, the use of diathermy is not recommended.

\section{Success rates and determinants of success}

Given that the probability of success in resolving a child's hydrocephalus is important to the clinical decision to utilize ETV, a predictive method to make this determination would be invaluable. Several investigators have sought to estimate success rates of ETV in a variety of settings to work toward a predictive model and identify optimal candidates for ETV, sometimes with conflicting results. Table 1 documents recently reported case series $(n \geq 10)$ analyzing success rates and their determinants. These data underscore the variability intrinsic to ETV outcomes, which is driven by experience and methodologies, procedural indications, and individual patient and study characteristics.

Regarding indicators of outcome, Kulkarni et al. sought to validate a success score based upon age at ETV, cause of hydrocephalus, presence of a previous CSF shunt, and center with high operative volumes ( $>100$ ETV cases performed) and stratified patients based on their scores to retrospectively evaluate the likelihood of ETV failure during long-term follow-up. They concluded that a high ETV success score correlated with a greater reliability of ETV compared to CSF shunts immediately after surgery, whereas this benefit was not attained among lower ETV success scorers until 3 to 6 months after surgery [30]. In determining the ETV success score, patient age was implicated as the strongest predictor of success; older children ( $>6$ months) typically experienced superior outcomes versus their younger counterparts [31]. Peretta et al. also reported similar results for both primary and secondary ETV procedures, as a repeat ETV was found to be more successful in establishing long-term shunt-free resolution of hydrocephalus following initial ETV failure when the initial ETV was performed at age 2 or older and in the absence 
Fig. 1 Illustration of the standard right frontal endoscopic approach $(\mathbf{a}, \mathbf{b})$ in a 14-year-old male with a history of aqueductal stenosis secondary to a tectal glioma treated by endoscopic third ventriculostomy. After visualization of the floor of the third ventricle (c), an adequate stoma was created with a NeuroBalloon catheter (d) with subsequent ascertainment that no basal cistern membranes were present (e). (Adopted with permission from Guzman et al. [29]) a

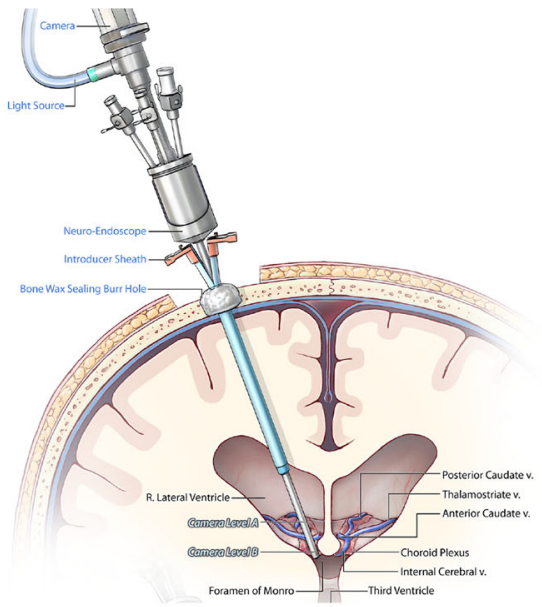

b

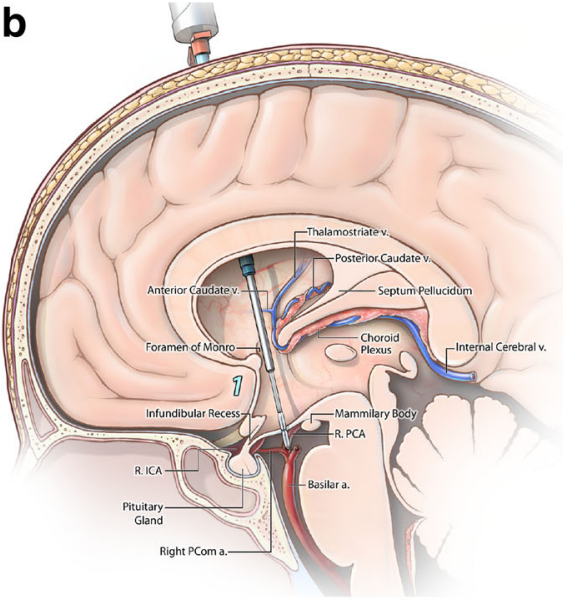

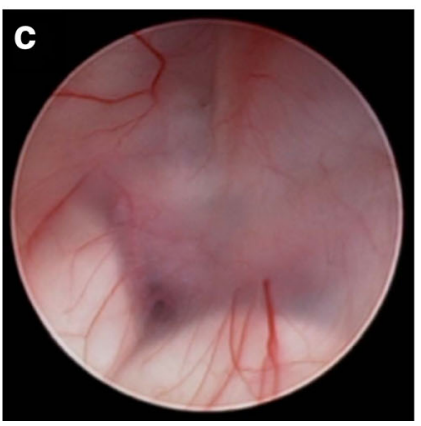
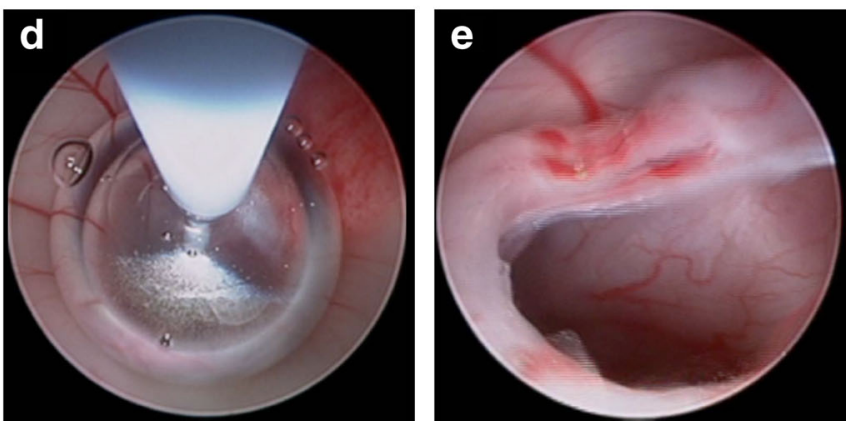

of arachnoid scarring [32]. For children under the age of 2 years, probability of ETV success increases gradually over the first few months of life [16]. Ogiwara et al. reported similar observations, noting ETV to be an effective first treatment option for hydrocephalus in patients under 6 months old, particularly for those between 3 and 6 months of age [33]. However, with results in direct contrast to aforementioned sources in such an age group, the controversy as to whether ETV is superior to shunt placement in infants continues. Although precise etiologies remain controversial, some posit that ETV failure in the first few months of life may be related to CSF pathway reclosure due to a tendency to form new arachnoid membranes in younger infants. Another theory suggests that the open cranial suture in infants with a relative low intraventricular pressure leads to a limited differential pressure gradient across the third ventricular floor. This would favor failure of the stoma. A limited CSF absorptive capacity in the first few months could also potentially contribute to this ETV failure [34].

Other factors influencing ETV success in infants include gestational age at birth, etiology and manifestations of the first episode of hydrocephalus, degree of choroid plexus cauterization, intraoperative assessment of cerebral aqueduct patency and cisternal scarring, and thickness of the third ventricle floor, with thinner floors correlating with improved outcomes [35-38]. Additionally, more recent outcome analyses based on the work of Warf in Uganda seem to suggest that ETV alone is generally not as effective in young infants under the age of 1 year versus their older counterparts, with the sole exception being post-infectious aqueductal obstruction, where ETV was equally effective across age groups [39]. In all other instances, as described below, Warf found ETV in combination with choroid plexus cauterization (CPC) to be superior to ETV alone, potentially avoiding the long-term dangers of shunt dependency in both industrialized and developing settings $[14,39]$.

Identifying metrics of improvement is important to assessing operative success rates. Considerable controversy exists regarding which metrics are most appropriate. A reduction in third ventricular volume as calculated on CT imaging is a helpful tool to follow improvement in patients after ETV. Schwartz et al. noted that degree of change correlated well with the duration of preoperative symptoms [40]. Third ventricular width and mid-sagittal cross-sectional area measured on magnetic resonance (MR) imaging can also be used to assess the success of ETV [41]. Ventricular volume after ETV decreases postoperatively but remains at supranormal values stabilizing at 3 to 6 months [42]. Volumetric assessment of CSF spaces in post-ETV MR imaging shows enlargement of subarachnoid spaces in concordance with decreases in ventricular volume as an indicator of ETV efficacy [43]. Garg et al. found that decreased third ventricular volume post-ETV does not appear to correlate well with clinical improvement and suggested that improvement in cerebral perfusion on SPECT imaging may be a better surrogate measure [44]. 


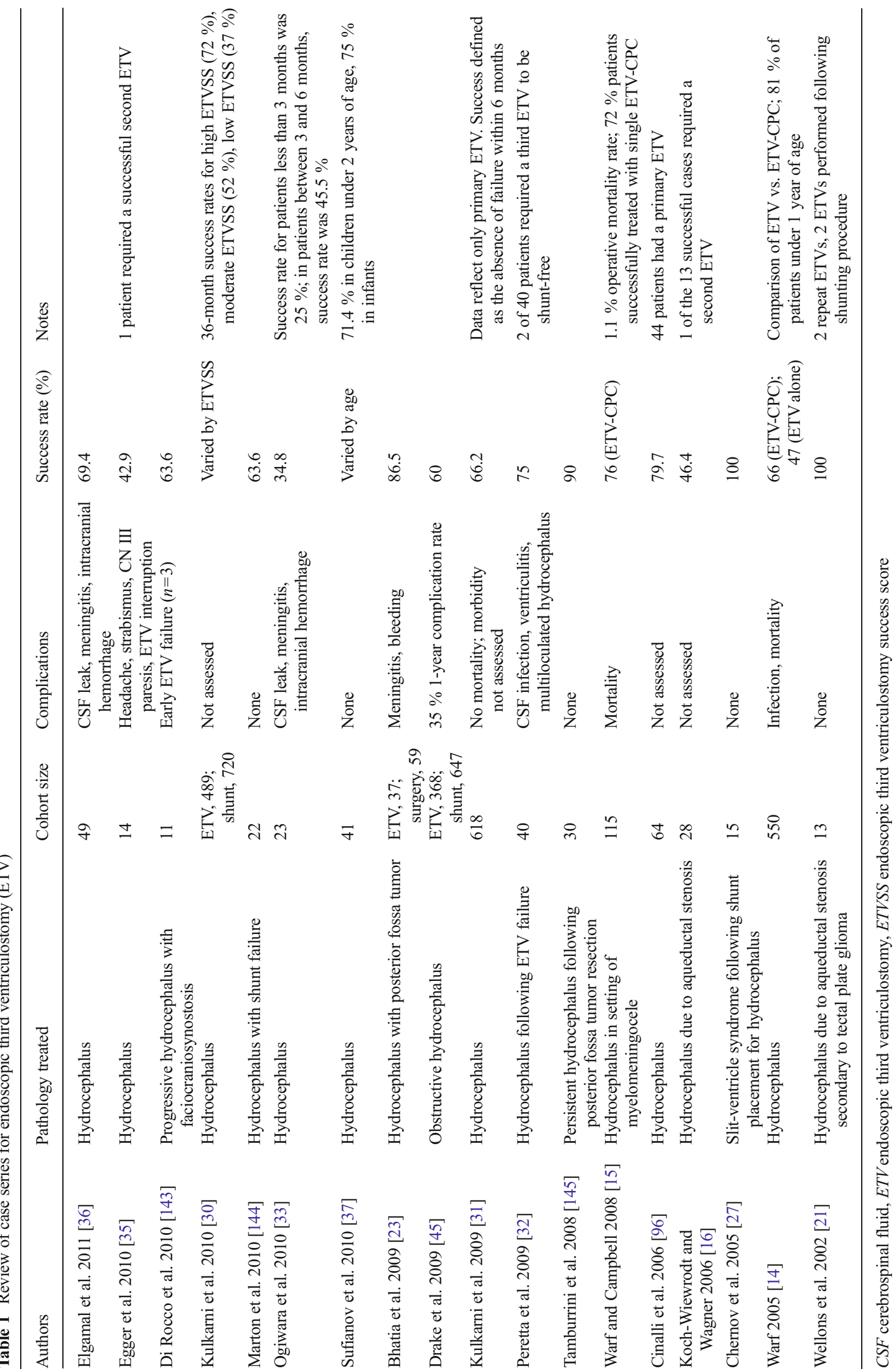


Quantitative analyses also prove vital when comparing ETV to other techniques such as ventriculoperitoneal shunts. Drake et al. conducted a large retrospective comparison of these techniques with results corroborating the general hypothesis that ETV success correlates with patient age. However, they also noted that that ETV provides no additional benefit to patients in terms of quality-adjusted life years (QALY) 1 year following surgery when compared to shunting [45]. Similar studies seem to report a similar lack of benefit in quality-of-life following ETV versus shunting [46]. Such findings underscore the need for continued research on quality indicators and reviews to optimize successful outcomes for pediatric hydrocephalus.

\section{Complications}

Though less invasive than non-endoscopic approaches, ETV nonetheless carries an appreciable risk of intraoperative and postoperative complications. Earlier reports of postoperative complications in the early stages of pediatric neuroendoscopy included hyperphagia, diabetes insipidus, CSF leaks, and amenorrhea [47]. Our review of recent literature (Table 1) reveals that some of the more common complications include CSF leaks, ventriculitis, meningitis, intracranial hemorrhage, and early ETV failure. Of these, hemorrhage is perhaps the most challenging intraoperative complication to manage due to the difficulty of obtaining hemostasis with endoscopic instruments [48]. As reported by Peretta and colleagues, the overall complication rate for such operative procedures is roughly $7.3 \%$, with CSF leaks, aborted procedures, and intraventricular hemorrhages reported as the most common causes of morbidity [49]. A number of other reported complications, albeit far more rare, include subdural hygromas, wound infections, and endocrine disturbances [48-52]. Regarding associated endocrine dysfunction secondary to intraoperative manipulation, the precise mechanism remains unknown, but possible involvement of the tuber cinereum, a component of the hypothalamic-pituitary axis, is implicated [53]. Similar complications and complication rates have been reported in the septostomy literature, including injury to structures on the lateral ventricle floor and third ventricle roof, meningitis, and significant intraventricular hemorrhage [54, 55]. Ultimately, when employed in appropriate clinical settings by highly trained and experienced personnel, and in conjunction with surveillance to preempt emerging morbidities, procedures such as ETV and endoscopic septostomy may be performed with fewer and less severe complications, thereby enhancing benefits to patients.

\section{ETV and choroid plexus cauterization}

Early attempts at hydrocephalus management involved choroid plexus resection or cauterization. In 1922, Dandy utilized a rigid ventriculoscope to endoscopically extirpate the entire choroid plexus in a case that was ultimately unsuccessful [3]. However, such efforts led to the development of endoscopic CPC techniques for hydrocephalus management, as first performed by Putnam in 1934 [56]. Putnam, Scarff, and Feld subsequently developed improved endoscopes enabling them to perform CPC in a limited number of patients with success rates as great as $80 \%$ between 1946 and 1952 [57]. Despite these attempts, mass appeal to implement endoscopic CPC remained limited for several decades given mixed long-term results, poor technological capacity, lack of appropriate patient selection, and a high degree of mortality.

With advances in endoscopic technology, endoscopic CPC enjoyed a re-emergence in the 1970s. Pople et al. published their results on the use of CPC in 104 pediatric patients with hydrocephalus where they were able to achieve long-term, shunt-free hydrocephalus control in $35 \%$ of patients [58]. The low success rates of CPC alone may be enhanced if used in combination with ETV. More recently, Warf has been credited for introducing CPC in combination with ETV for hydrocephalic infants with a low degree of mortality and infection, even in resource-limited settings [14, 39, 59]. In his work, comparing outcomes of 266 children undergoing ETV-CPC compared to 284 children undergoing ETV alone, the success rate for ETV-CPC was significantly higher than ETV alone among infants younger than 1 year of age. Use of a flexible endoscope and electrocautery attached to a Bugby wire enabled cauterization of the choroid plexus in the lateral and third ventricles in addition to the temporal horns. A septostomy was performed to gain access to the contralateral choroid plexus [14]. A subset of infants with non-postinfectious hydrocephalus with closed aqueducts as well as infants with post-hemorrhagic hydrocephalus do not seem to respond well to ETV-CPC procedures. Chamiraju et al. studied ETV-CPC in 27 infants with post-hemorrhagic hydrocephalus of infancy and found a $63 \%$ failure rate. The majority of such failures occurred within the first 3 months of treatment [60]. Some authors have suggested using MRI FIESTA imaging to identify the subset of post-hemorrhagic hydrocephalic infants that could respond well to ETV-CPC, especially those with a lack of cisternal scarring [61]. Patient selection in terms of aqueductal patency and cisternal scarring appears to be paramount in achieving success with using ETV-CPC procedure [38].

\section{Future avenues}

Despite centuries of experience with hydrocephalus and decades of experience with ETV, much remains to be uncovered in order to achieve significant improvements in patient outcomes following therapeutic intervention. Important recent advances to standard clinical technique, particularly in terms of navigation and visualization, include virtual neuroendoscopy using magnetic resonance and 3-D ultrasound images to plan approaches for complex anatomy, electromagnetic guidance to 
obviate the need for rigid head fixation in the pediatric setting, and the introduction of high-definition camera equipment for superior visualization of the operative field [62-64].

Collaboration across disciplines is required to enhance our basic science understanding of the pathophysiology of hydrocephalus, to develop more powerful mathematical models to identify appropriate candidates for the various treatment options, and to devise the technologies required to implement those treatment strategies in the safest, most effective way possible [65]. Recent literature suggests the possible utility of transforming growth factor beta-1 (TGF- $\beta 1$ ) in differentiating between obstruction versus hyporesorption as the etiology of post-hemorrhagic hydrocephalus in premature newborns, acting as a biomarker to both highlight a potentially important factor in condition development as well as treatment guidance to resolve it [66]. A collection of advanced neuroendoscopes, imaging platforms, and robotic devices, in addition to broadened training opportunities, will hopefully continue to improve outcomes and extend available techniques to patients in more limited clinical settings. Similarly, other exciting possibilities in hydrocephalus treatment on the horizon include in utero neuroendoscopic treatment of the pathology, which, if successful, could halt the disease process prior to the onset of irreversible brain damage [13, 67].

\section{Septostomy for trapped lateral ventricle}

Another form of hydrocephalus important to note in which endoscopic-aided procedures have proven useful is in the setting of isolated lateral ventricular hydrocephalus secondary to unilateral obstructions at the foramen of Monro. In these cases, endoscopic septostomies may be performed to form a communication between the lateral ventricles, which have been demonstrated to eliminate the need for CSF shunting or ventricular catheters altogether [68-70]. However, results for such procedures have been mixed. Aldana et al. reported initial successful outcomes in 17 of 32 patients (53\%) upon first procedure and an overall patency rate of $81 \%$ (26/32) including repeat septostomies. The authors concluded that a history of multiple previous shunt procedures was highly predictive of initial septostomy failure, increasing failures rates almost fivefold [54]. More recent series have reported similar rates of success following initial septostomy, with significant rates of failure in pediatric populations less than 6 months of age [71].

\section{Endoscopic cyst fenestration, decompression, and resection}

Intracranial cysts are often seen in the pediatric population located in the intraventricular, paraventricular, cisternal, or subarachnoid spaces. These cysts are often discovered fortuitously and are asymptomatic and do not require treatment. On the other hand, the cysts can cause mass effect, intracranial hypertension, deformity, and neurologic deficits requiring treatment. Given that cystic lesions usually follow a benign clinical course, treatments for symptomatic lesions must be equally benign to the patient. As such, neuroendoscopes have been successfully utilized in a wide variety of intracranial cysts necessitating fenestration or resection [72]. Although extensive literature documents the use of neuroendoscopes for treatment of pediatric hydrocephalus, there is limited literature for their use in pediatric intracranial cysts, and as such, much of the discussion on this topic below derives from adult endoscopy literature. Herein, we aim to discuss endoscopic approaches to (1) arachnoid cysts, (2) intraventricular cysts (i.e., colloid cysts, pineal cysts, etc.), and (3) cystic suprasellar tumors (i.e., craniopharyngiomas).

\section{Arachnoid cysts}

Arachnoid cysts are congenital, typically asymptomatic cystic collections of cerebrospinal fluid within the subarachnoid space first described by Bright in 1831 [73, 74]. They account for $1 \%$ of all non-traumatic intracranial mass lesions, usually arising within and expanding the margins of CSF cisterns rich in arachnoid $[75,76]$. Given such a mechanism of pathophysiology, arachnoid cysts may occur anywhere, but most commonly present within the middle cranial fossa [77-79].

When symptomatic, arachnoid cysts typically present with local mass effect on neural tissue and obstruction of CSF flow and macrocephaly in younger children in addition to other potential symptoms including headache, head bobbing, focal neurologic deficits, seizures, and even psychomotor retardation to varying degrees. Additionally, there remains a risk of post-traumatic extradural and subdural hemorrhage and subdural hygromas in such instances.

In symptomatic arachnoid cysts, treatment indication is usually given without much debate. In infants, a pathologic increase (symmetric and asymmetric) in head circumference would be considered a surgical indication. However, considerable debate continues to exist in the management of asymptomatic arachnoid cysts, in infants and older children [80]. In determining whether asymptomatic cysts merit intervention, whether by endoscopic or open approach, given possible risks such as the hindrance of normal brain development, subdural hematomas, and subdural hygromas, surgeons must carefully consider each case individually. Current evidence remains limited on predictive factors that may individuate those cases that may benefit most from intervention [77, 81-86]. The author does not advocate treatment in asymptomatic arachnoid cysts. Especially in older children, the causality of minor symptoms must be analyzed in detail to avoid unnecessary surgery. 
Arachnoid cysts can be treated with a number of neurosurgical options dependent upon location. The underlying treatment goal is to drain or divert the contained CSF within the arachnoid cyst. The described approaches include stereotactic aspiration, craniotomy with excision of cyst, cyst fenestration, cystocisternostomy, ventriculocystostomy, and cystoperitoneal shunting [87]. Recent advances in neuroendoscopy have resulted in most of the arachnoid cysts being treated with endoscopic fenestration $[88,89]$. This approach has the advantage of significantly reducing the size of the cyst and precludes the need for cystoperitoneal shunt placement. The fenestration must be completed either into a nearby cistern or into the closest abutting ventricle in an attempt to create a single CSF space, thus providing the greatest chance of cure.

Several recently published case series documenting the practicality of neuroendoscopy for treating arachnoid cysts is presented in Table 2. These endoscopic approaches have been modified by burr hole location and use of stereotaxy to allow for fenestration of quadrigeminal [87, 90], suprasellar [75, 91-94], middle fossa [79], prepontine [95], interhemispheric [96], retroclival [97], and third ventricular arachnoid cysts [94] with satisfactory outcomes.

Success of endoscopic fenestration in the setting of middle fossa arachnoid cysts is well-documented [91, 98, 99]. In work by Spacca et al., $90 \%$ of the pediatric cohort treated demonstrated clinical improvement, and $73 \%$ of cysts treated reduced in size or completely resolved following intervention [79]. Charalampaki et al. described a group of 13 pediatric patients who underwent neuroendoscopic suprasellar cyst fenestration; seven of these patients who had prior shunts placed remained shunt-free afterwards with no complications noted [100]. Similarly, Ersahin et al. suggested endoscopic surgery as first-line treatment for suprasellar cysts after reporting a series of 17 patients, where only three required ventriculoperitoneal shunting following ventriculocystocisternostomy [75]. These studies seem to indicate that neuroendoscopy is a safe approach for the fenestration of suprasellar arachnoid cysts with a high success rate and low likelihood of necessary postprocedural shunting. For infants with large hemispheric arachnoid cysts, the success rate of endoscopic fenestration is less favorable than in older children; therefore, some authors advocate shunting those primarily in light of low endoscopic success rates [34, 60]. The author will advocate a neuroendoscopic approach if possible. It is critical to discuss the limited success rate in infants with large cysts. The possible need of a secondary cysto-peritoneal shunting in case of neuroendoscopy failure is always discussed prior to the intervention.

While these success rates for endoscopic fenestration are encouraging, endoscopic techniques face similar postoperative challenges as open techniques for treatment of arachnoid cysts. In the Spacca series, five patients developed subdural hygromas while an additional five patients developed postoperative subdural hemorrhage requiring surgical treatment [79].
Cinalli et al. used neuroendoscopic techniques for treatment of interhemispheric arachnoid cysts in a series of five patients and noted success with a single procedure in only three patients. However, three patients $(60 \%)$ developed subdural CSF hygromas postoperatively due to a thin cerebral mantle and associated hydrocephalus [96].

For less common arachnoid cysts, such as those within the quadrigeminal cistern, endoscopic cystostomy demonstrates a high success rate in combination with ETV, particularly in patients greater than 6 months of age [87]. In instances where cysts may extend into the third ventricle, a bipolar fenestration into the ventricle and basal cistern can help decompress the cyst and leave the patient shunt-free [94]. While endoscopy works well for most cysts where fenestration is an option, the technique may pose a problem in the presence of intervening brain tissue. In such scenarios and for small-sized cysts within hemispheric, temporal, or posterior fossa regions, microsurgery or shunting may prove to be the most reasonable option. However, generally, neuroendoscopy is first-line therapy in the treatment of arachnoid cysts due to high success rates with minimal rates of reoperation, shorter hospitalization courses, and avoidance of additional procedures such as shunt placement or craniotomy [101, 102].

\section{Intraventricular cysts}

Previously, microsurgical resection or ventriculoperitoneal shunting were the only means of treatment for patients with colloid and other intraventricular cysts. However, with advances in endoscopy and the ability to cannulate the lateral ventricle, navigate through the cerebrospinal fluid, and achieve greater visualization of capsular vascularity, neurosurgeons are now able to treat a number of intraventricular cysts in the pediatric population, including colloid, pineal, and porencephalic cysts in an additional manner (Table 3) (Figs. 2 and 3). Most lessons in this regard have been learned from larger series derived from adult neurosurgical literature due to a paucity of literature in the pediatric population [103].

Colloid cysts, which are posited to derive from the aberrant migration of endodermal elements to the velum interpositum during embryonic development, can produce obstruction most commonly at the foramen of Monro, thereby leading to obstructive hydrocephalus and risk of sudden death [104, 105]. Such cysts tend to most commonly occur between the second and fourth decades of life and are relatively rare in children. A number of surgical techniques have been described in the resection of colloid cysts, including shunting, microsurgery (interhemispheric, transcallosal, or transventricular), stereotactic aspiration, and endoscopic resection.

Endoscopic approaches, including both primary endoscopy and endoscopy-assisted keyhole approaches, have enjoyed general success when indicated for the resection of colloid cysts with evidence of shorter hospital stays, rapid 


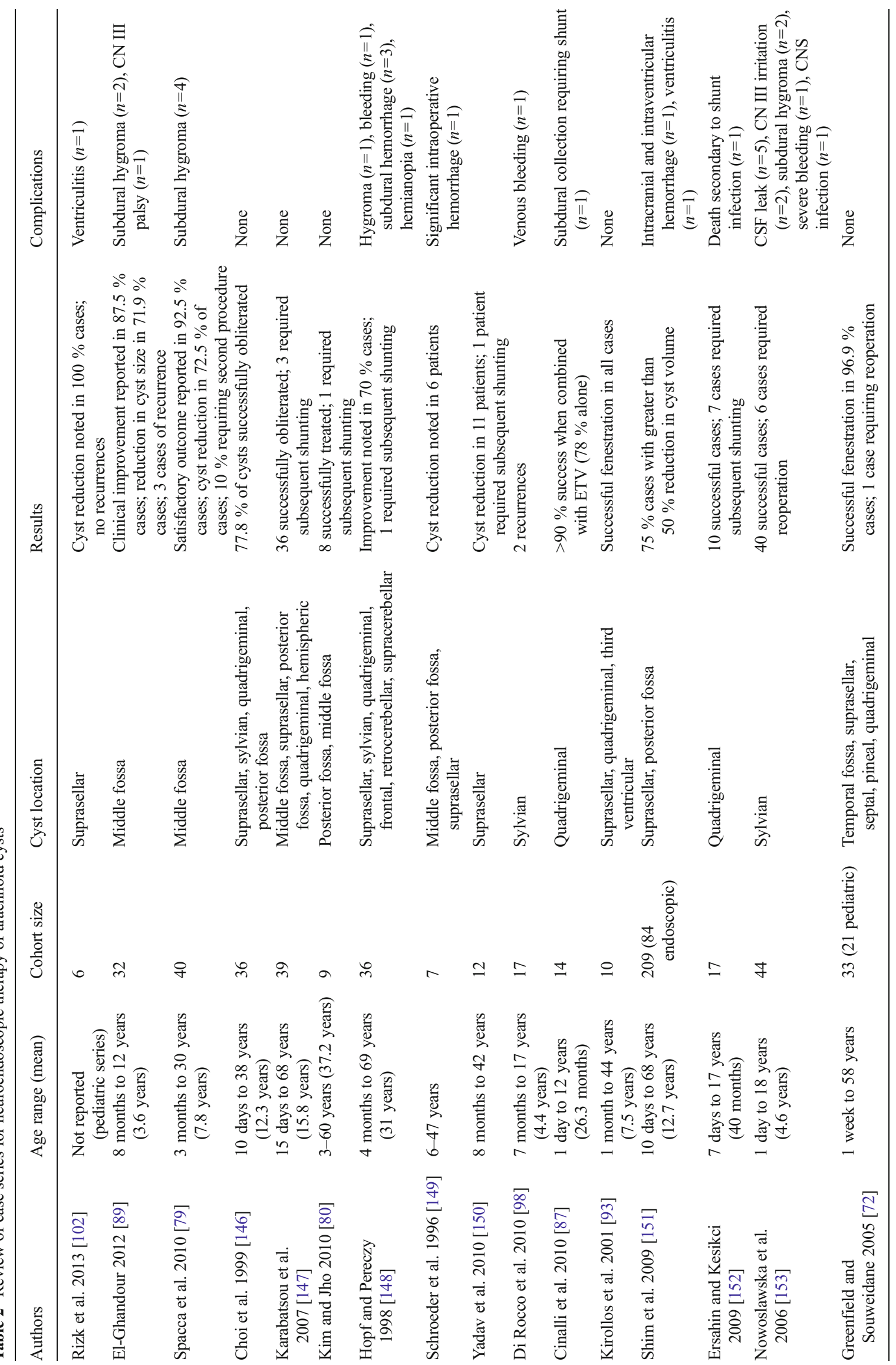




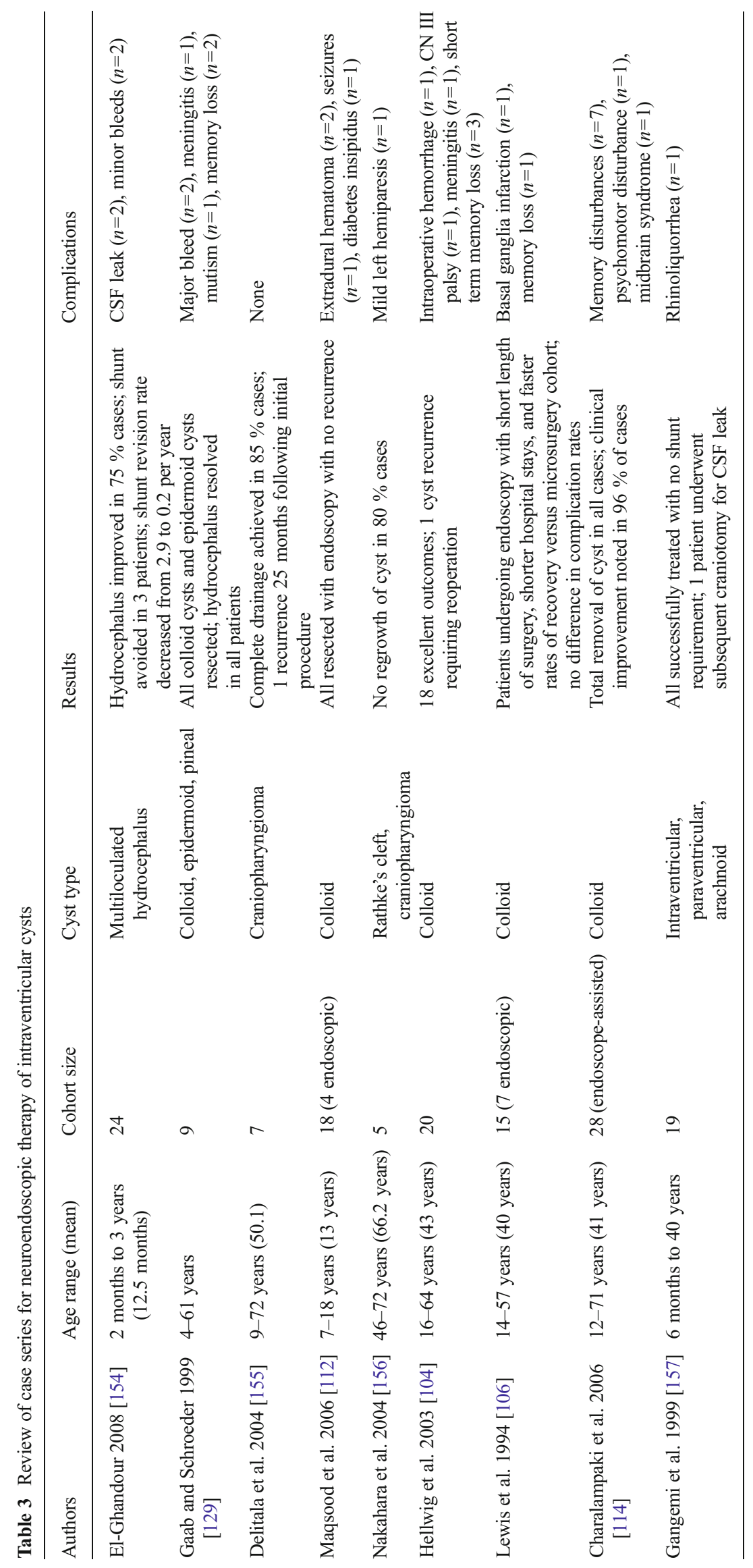


Fig. 2 Five-year-old with a radiologically enlarging left ventricular cyst presenting with headache. Preoperative T2weighted axial (a) and sagittal (b) MR imaging demonstrate a $5-\mathrm{cm}$ intraventricular cyst. A left occipital endoscopic approach was chosen for the endoscopic cyst fenestration (c) with care made to reach both the occipital and frontal pole of the cyst to restore normal CSF pathways within the lateral ventricle (f). Postoperative MRI demonstrates decompression of the left lateral ventricle $(\mathbf{d}, \mathbf{e})$
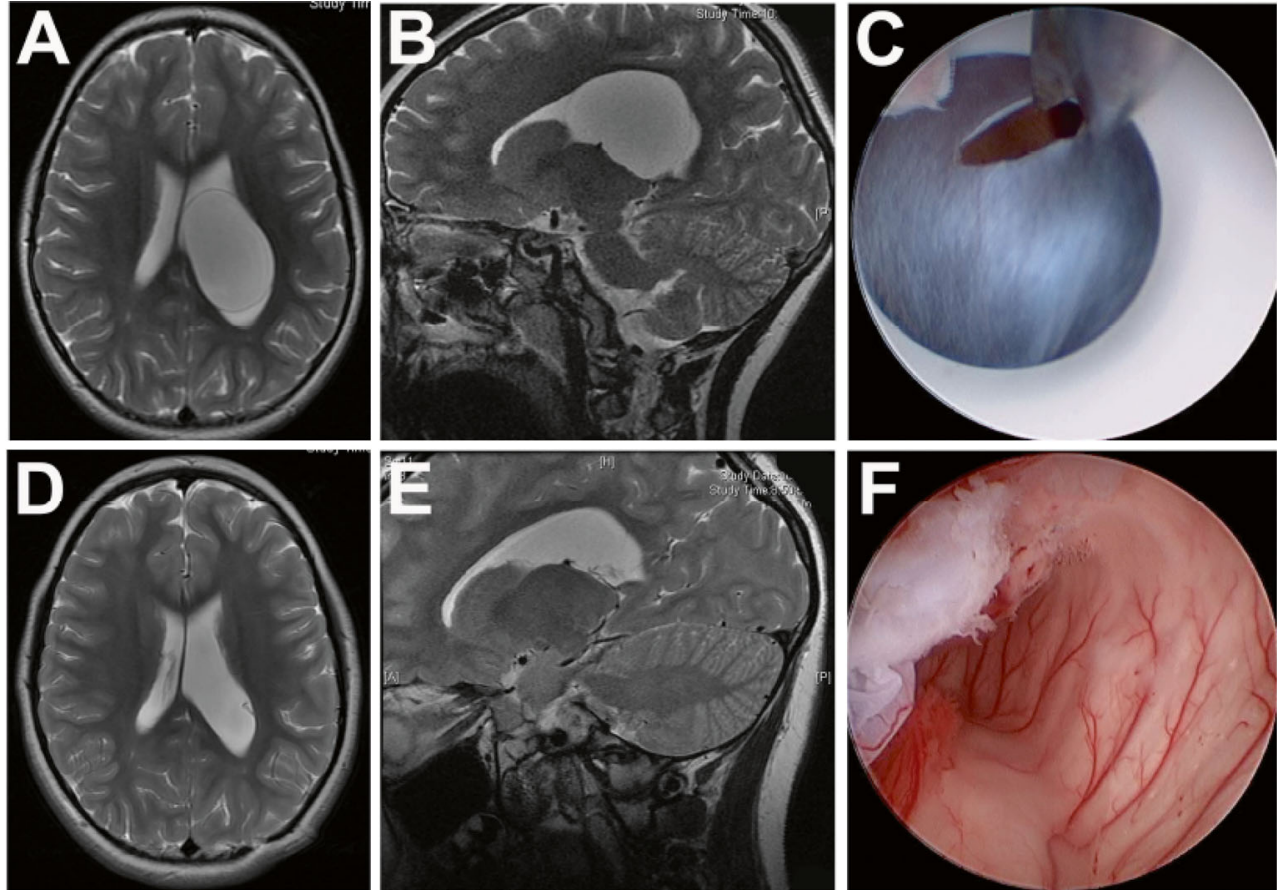

postoperative recoveries, and a lesser degree of complications and recurrence versus microsurgically resected tumors even during long-term follow-ups [106-110]. Powell et al. reported the first such successful resection in 1983 [111]. More recently, further case series have confirmed the feasibility and efficacy of lesion resection [112]. Teo described his experience with 18 patients, including one pediatric patient who underwent complete endoscopic removal of colloid cysts with no recurrence. Two patients developed aseptic meningitis postoperatively without any neurologic sequelae [113]. In the case of endoscope-assisted microsurgical approaches, Charalampaki et al. described colloid cyst resections in 28 patients with gross total resection and no recurrence. Postoperative complications included mild memory disturbances, psychomotor retardation, midbrain syndrome, and meningitis in limited cases [114].
Fig. 3 Four-year-old with a complex history of hydrocephalus and multiloculated ventricles (a, b). Endoscopic fenestrations of multiple intraventricular compartments was performed (d, e) followed by endoscopyassisted shunt placement $(\mathbf{c}, \mathbf{f})$ into the right temporal horn
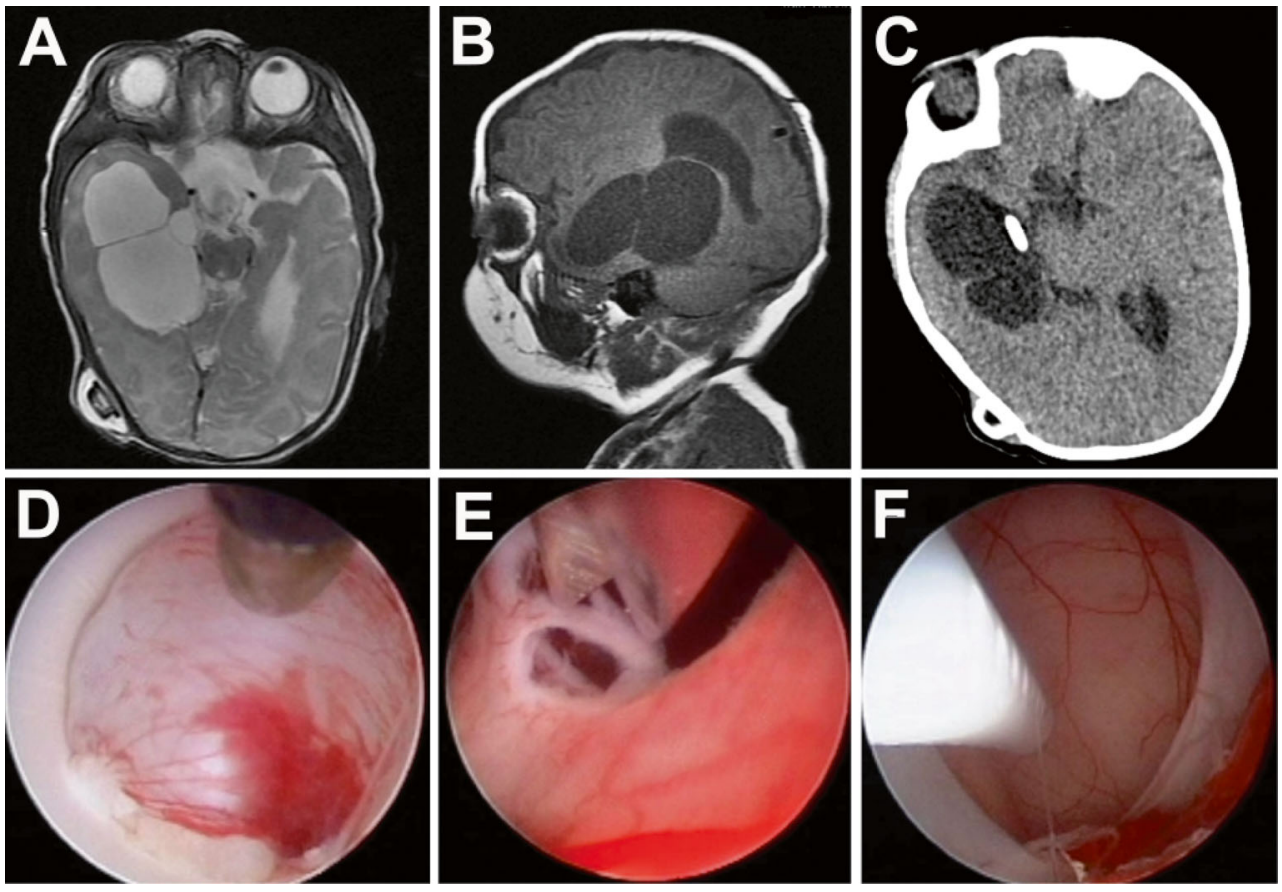
Cystic suprasellar tumors

A wide variety of surgical approaches exist in the treatment of cystic mass lesions, but many are technically difficult and fail to remove such masses in full without significant risk to surrounding structures dictating neurologic and endocrine function. As such, endoscopic transventricular approaches, particularly for craniopharyngiomas and cystic optic hypothalamic tumors, have evolved. While literature on the indication is generally sparse, published small case series suggest endoscopic management of suprasellar cystic lesions to be an effective alternative to open approaches, with negligible rates of complication and recurrence. Recent evidence suggests that a multimodal approach incorporating neuroendoscopy alongside microsurgery and radiosurgery may lead to improved tumor control and cognitive outcomes versus radical resection alone $[115,116]$. Primary treatment of the cystic component can lead to decreased mass effect and restoration of open CSF pathways, thus delaying the need for radiation therapies especially in young children.

Surgical management of pediatric craniopharyngiomas remains a hotly contested issue, with a recent shift from gross total resection, given the potential for hypothalamic insult and associated complications, to limited resection in conjunction with multimodal therapy [117-119]. One such therapyplacement of intracystic catheters to treat craniopharyngiomas via direct injection of chemoradiotherapeutic agents - can be facilitated by endoscopic guidance, thus providing a minimally invasive method to deliver potent antineoplastic agents (i.e., bleomycin) directly to the tumor site $[120,121]$. The safety and efficacy of such an approach was recently documented in three cases by Mori et al. in which no complications occurred with placement of Ommaya reservoir catheters over the outer surface of a transparent endoscopic sheath [122]. Given that $90 \%$ of craniopharyngiomas are reported to have a cystic component, such a technique provides an effective approach in lesion management [123].

Technique for cyst fenestration and decompression

The patient's head is positioned so that it allows the shortest linear distance to the cyst. Stereotactic image guidance can be used to find the best site for the surgical incision. A 2-cm linear incision is made over the identified site of insertion. A burr hole is placed over the area, and the dura is bipolared and opened in a standard cruciate fashion. A small cortical opening is completed that allows a peel-away sheath to be introduced into the ventricular cavity. Typically, the endoscope is introduced through the peel-away sheath and the cyst wall is identified under endoscopic view. Endoscopic forceps and scissors are subsequently employed to make a small opening in the cyst wall, which is further enlarged using a double balloon catheter. In instances of a vascularized surface, cautery can be used prior to incision of the cyst wall. It is critical to have an ample opening to allow cyst drainage into a ventricle or a CSF cistern. Use of an endoscope allows visualization of the cyst contents, helps determine the site of cyst fenestration, and allows avoidance of critical neurovascular structures (Fig. 2).

For Sylvian cysts and other superficial cysts, it is important to plan the burr hole such that it creates an ideal trajectory to the basal cisterns. Stereotactic navigation can be utilized to plan optimal burr hole positioning as necessary. Particularly in the case of tumor-associated cysts (i.e., craniopharyngiomas), biopsies of the cyst wall and CSF sampling for further analysis are recommended.

\section{Endoscopic biopsy and resection of pediatric brain tumors}

Tumors arising within the ventricles of the brain traditionally represent a major challenge. Such lesions located deep within the brain must be approached from a considerable distance through normal brain structures, which can be particularly detrimental in the pediatric population.

First documented by Fukushima in 1978, neuroendoscopy can play a significant role in the clinical management of intraand para-ventricular pediatric tumors, including pineal region tumors, optic hypothalamic gliomas, hypothalamic hamartomas, and craniopharyngiomas, given its diagnostic and therapeutic capabilities [124]. While surgical resection is the mainstay treatment for suprasellar tumors in adults, given the distinct behavior and increased chemoradiosensitivity of tumors more common within the pediatric population, biopsy is the initial therapy of choice to accurately diagnose the pathology. As such, endoscopy, which minimizes the degree of manipulation to surrounding normal brain structures, reduces associated rates of morbidity and mortality, and enables visualization of tumor capsule vasculature, presents a particularly attractive option in the management of pediatric malignancies (Table 4).

\section{Technique}

The technical approach for endoscopic biopsy of pediatric brain tumors is determined by the location in or adjacent to the ventricular system. Lesions near the foramen of Monro and the frontal horns of the lateral ventricle can be approached with a standard ETV frontal burr hole just anterior to the coronal suture (Fig. 4). Lesions located more posteriorly within the third ventricle require a more anterior frontal burr hole to allow easy access with the rigid endoscope. The degree of angulation and maneuverability is limited with the rigid 
Table 4 Review of case series for neuroendoscopic pediatric brain tumor biopsy

\begin{tabular}{|c|c|c|c|c|c|}
\hline Authors & Pathology treated & $\begin{array}{l}\text { Cohort } \\
\text { size }\end{array}$ & Complications & $\begin{array}{l}\text { Success } \\
\text { rate }(\%)\end{array}$ & Notes \\
\hline $\begin{array}{l}\text { Kim et al. } \\
2013[136]\end{array}$ & $\begin{array}{l}\text { Suprasellar tumors of } \\
\text { various types }\end{array}$ & 23 & Transient DI $(n=3)$ & 95.7 & $\begin{array}{l}\text { Biopsy limited in } 1 \text { case due to small } \\
\text { lateral and third ventricular size in } 1 \\
\text { case }\end{array}$ \\
\hline $\begin{array}{l}\text { Ahn and } \\
\text { Goumnerova } \\
2010[158]\end{array}$ & $\begin{array}{l}\text { Intra- or periventricular } \\
\text { tumors of various types }\end{array}$ & 31 & $\begin{array}{l}\text { Intraventricular hemorrhage }(n=1) \\
\text { intraparenchymal hemorrhage }(n=1)\end{array}$ & 70 & $\begin{array}{l}\text { Majority of biopsies performed } \\
\text { in conjunction with CSF-diverting } \\
\text { procedures (e.g., ETV, fenestration } \\
\text { of septum pellucidum) }\end{array}$ \\
\hline $\begin{array}{l}\text { Song et al. } \\
2010[159]\end{array}$ & $\begin{array}{l}\text { Intra- or periventricular } \\
\text { tumors of various types }\end{array}$ & 49 & $\begin{array}{l}\text { Postoperative bleed requiring operation }(n=1) \text {; } \\
\text { CSF leak }(n=1) \text {, central DI }(n=2), \text { EVD } \\
\text { infection }(n=1), \text { EOM limitations }(n=4)\end{array}$ & 91.8 & \\
\hline $\begin{array}{l}\text { Depreitere et al. } \\
2007[160]\end{array}$ & $\begin{array}{l}\text { Intraventricular tumors } \\
\text { of various types }\end{array}$ & 31 & $\begin{array}{l}\text { Postoperative vegetative state }(n=1) \text {, } \\
\text { intraoperative bleed }(n=1) \text {, postoperative } \\
\text { hemorrhage }(n=2) \text {, ventriculitis }(n=2), \\
\text { sodium imbalance }(n=2)\end{array}$ & 69 & $\begin{array}{l}\text { Intraoperative bleeding noted } \\
\text { in } 17 \text { cases }\end{array}$ \\
\hline $\begin{array}{r}\text { Souweidane } \\
2005[55]\end{array}$ & $\begin{array}{l}\text { Intraventricular tumors } \\
\text { of various types }\end{array}$ & 26 & None & 96 & $\begin{array}{l}\text { ETV performed simultaneously } \\
\text { to treat hydrocephalus in setting } \\
\text { of posterior third ventricular } \\
\text { tumor or pineal mass }\end{array}$ \\
\hline $\begin{array}{l}\text { Yamini et al. } \\
2004 \text { [161] }\end{array}$ & $\begin{array}{l}\text { Pineal region tumors } \\
\text { of various types }\end{array}$ & 7 & $\begin{array}{l}\text { Aborted biopsy due to excessive } \\
\text { bleeding }(n=1)\end{array}$ & 57.1 & $\begin{array}{l}\text { ETV performed simultaneously } \\
\text { to treat associated hydrocephalus }\end{array}$ \\
\hline $\begin{array}{l}\text { Macarthur et al. } \\
2001[51]\end{array}$ & $\begin{array}{l}\text { Intra- or periventricular } \\
\text { tumors of various types }\end{array}$ & 16 & Intraoperative hemorrhage $(n=2)$ & 62.5 & 4 biopsies not diagnostic, 2 abandoned \\
\hline
\end{tabular}

$C S F$ cerebrospinal fluid, $D I$ diabetes insipidus, EOM extraocular movements, $E T V$ endoscopic third ventriculostomy, EVD external ventricular drain

Fig. 4 Seven-year-old with tuberous sclerosis and intraventricular tubers and a radiologically growing subependymal giant cell astrocytoma. The coronal (a) and axial post contrast MRI (b) demonstrates the intraventricular lesions. Endoscopic view of the lesions (c) and endoscopicassisted microsurgical resection of the tumor (d)
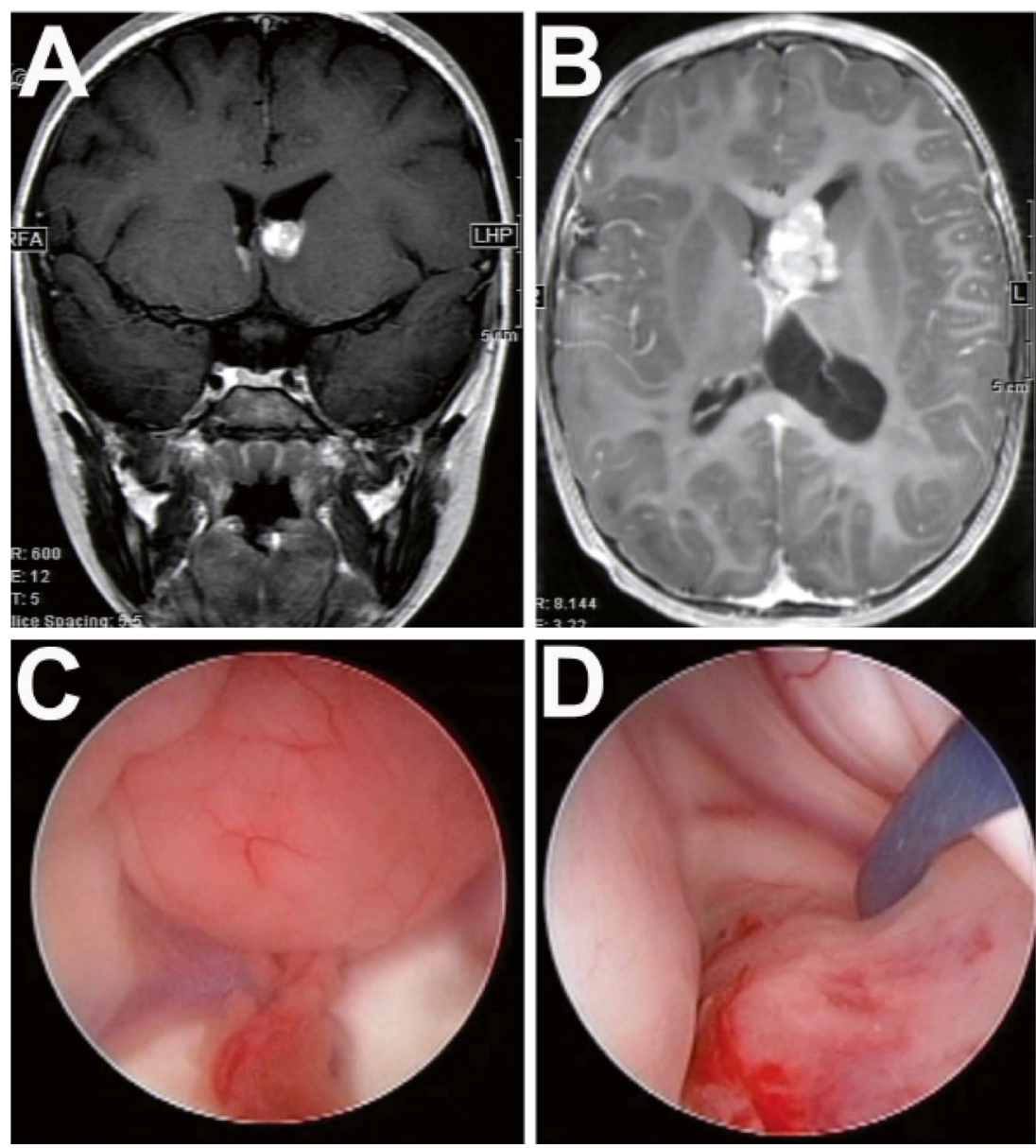

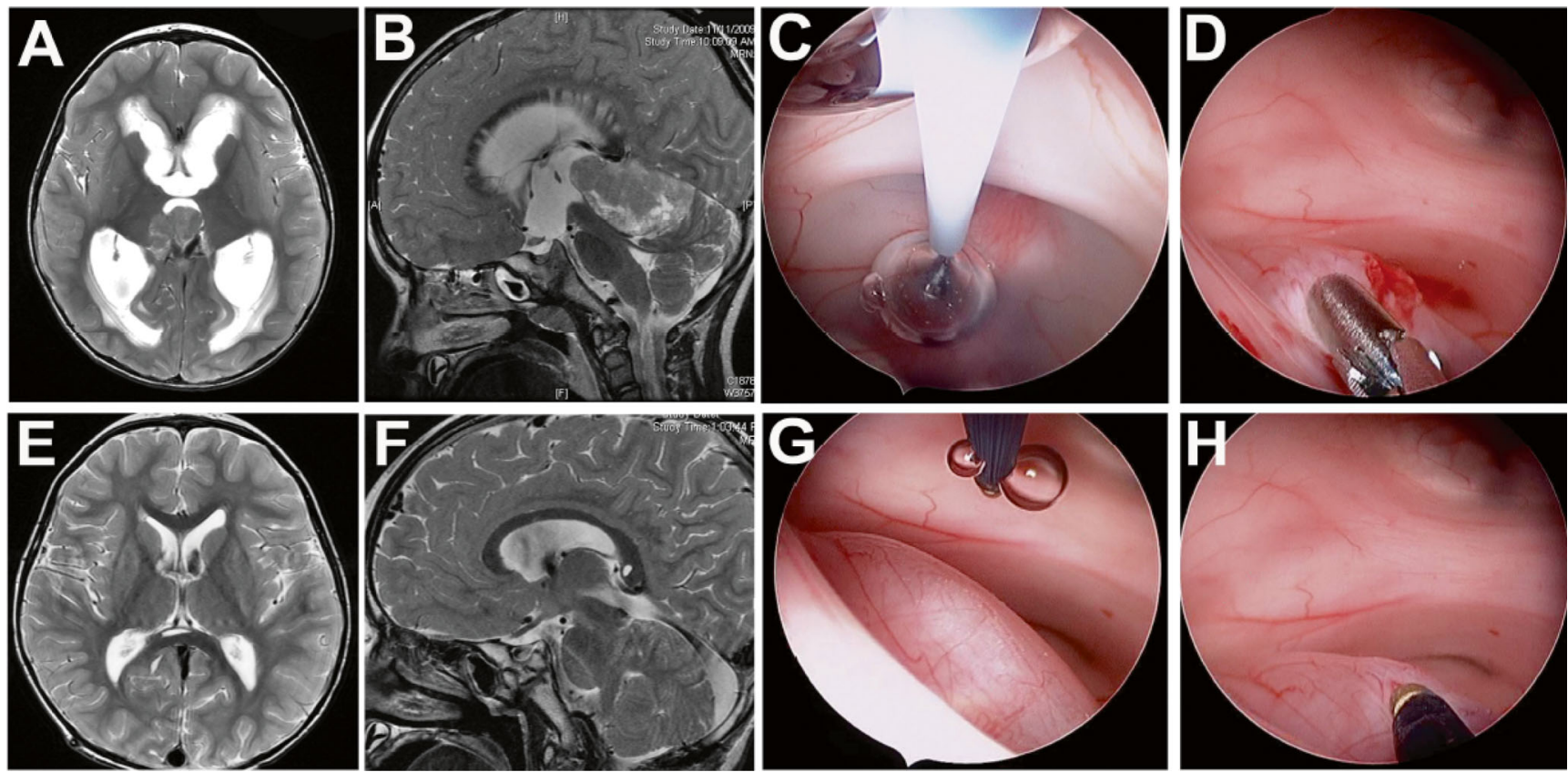

Fig. 5 Three-year-old presenting with progressive imbalance, nausea, and vomiting. Initial MRI demonstrated a large pineal region tumor extending into the third ventricle and significant obstructive hydrocephalus with periventricular edema (a, b). An endoscopic third ventriculostomy (c) followed by a tumor biopsy (d) was performed. The pathological diagnosis was pinealoblastoma, and a supracerebellar infratentorial approach was chosen for tumor resection. Follow-up MRI demonstrated resolution of the hydrocephalus (e) and a gross total tumor

resection was achieved (f). To reach the tumor, a burr hole was placed slightly more frontal than the classic Kocher's point. This, together with an enlarged foramen of Monro, allowed access to the posterior part of the third ventricle. To improve visualization and control of endoscopic instruments in the tumor, the endoscope was rotated $180^{\circ}$, placing the working channel close the lesion. g Prior to rotation, note instrument at 12 o'clock away from lesion. $\mathbf{h}$ Instrument at 6 o'clock with good access to the tumor

endoscopes, and, in some cases, two burr holes may be required for ETV and biopsy, respectively (Fig. 5). Stereotactic image guidance can be extremely useful in planning trajectories and the best location to place burr holes. Biopsy forceps and scissors can be used through the endoscope port to obtain an adequate biopsy specimen.

Some tumors may be hemorrhagic and bleeding may be encountered at the time of biopsy. In such situations, we recommend active irrigation with saline at the site of the biopsy to allow the blood to be washed away and to allow clear visualization of the bleeding site. Electrocautery can be extremely useful in these scenarios.

Flexible endoscopes are an alternative to rigid endoscopes. They allow greater degrees of freedom but this is at the expense of the optic quality [125]. One approach for biopsies in the posterior part of the third ventricle in combination with ETV is to place a single more frontal burr hole. The biopsy is performed using the rigid endoscope with benefit from excellent optics. The ETV can be performed through the flexible endoscope [14].

When the feasibility of a pure endoscopic approach is limited, an open microsurgical approach may be merited in the resection of an intraventricular mass. An endoscopicassisted endoport approach allows good microsurgical access combined with excellent lighting and visualization through the endoscope. The utility of such approaches has been noted

in the resection of colloid cysts, arachnoidal cysts, primitive neuroectodermal tumors, Rathke cysts, hypothalamic hamartomas, and other intraventricular masses, and seems to represent a new approach to the management of complex ventricular lesions [100, 114, 126-128].

\section{Success rates}

In experienced hands, neuroendoscopic biopsy and resection of pediatric brain tumors appears to be an increasingly safe and effective procedure [51, 55, 129-132]. The risks of clinically significant intraoperative hemorrhage necessitating abandonment of the procedure and postoperative bleeds are reported to be 2.3 and $3.5 \%$, respectively [133]. The results of endoscopic biopsy in the setting of hydrocephalus are largely favorable, with recent studies citing success rates as high as $96.0 \%[55]$.

In a recent multicenter study, Constantini et al. found that the technique provided meaningful pathological data for the majority of patients analyzed across a wide range of tumor types and locations with minimal morbidity and mortality. In analyzing 293 patients who underwent endoscopic biopsy for lesions across 13 centers in nine countries, biopsies were noted to be informative in 265 patients $(90.4 \%)$. In 14 cases $(17.9 \%)$ of those who underwent subsequent open surgery, a discrepancy was noted between sample pathological 
Fig. 6 Four-year-old with a complex history of congenital hydrocephalus and multiple ventriculoperitoneal shunt surgeries and revisions. The axial CT scan shows an orphan catheter from a previous surgery (a). The catheter was retrieved endoscopically (b) prior to an endoscopic septostomy and insertion of a new ventricular catheter
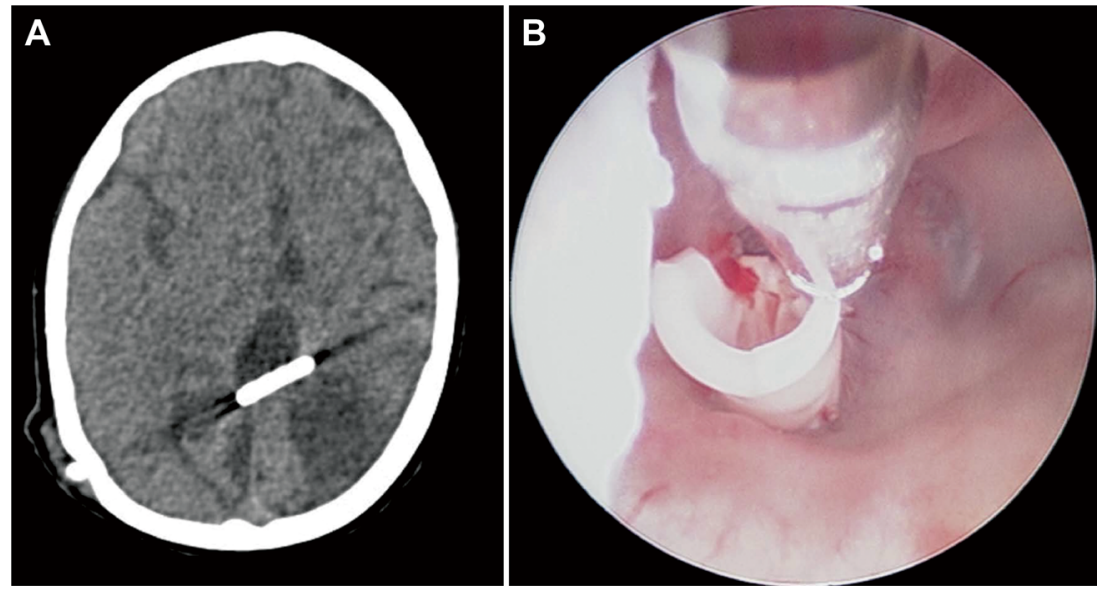

diagnoses, particularly in cases where biopsy results seemed to indicate a low-grade glial tumor. Of note, only one death was reported, which was attributed to significant intraoperative bleeding [134]. Such findings supporting the diagnostic accuracy of neuroendoscopic biopsy have also been reported elsewhere, particularly as advances in navigation-assisted systems have come to the forefront over the past decade $[135,136]$.

\section{Limitations}

While the advantages of combined ETV and tumor biopsy are obvious, the technique is limited to tumors that are intraventricular or protrude into the ventricular space. Other locations require the use of a conventional stereotactic biopsy, open craniotomy, or a transsphenoidal approach. A significant limitation for tumor resection is the narrow working channel with small instruments and their very limited degrees of freedom. Previous reports recommend such tumors should not exceed $2 \mathrm{~cm}$ in diameter given the degree of intraoperative time involved to resect such masses [129]. In cases where a pure endoscopic option is limited by anatomical barriers, such as small lateral and third ventricular spaces, combined microsurgical and endoscopic resection may prove of greater utility [126]. However, absence of hydrocephalus is not a contraindication to endoscopic surgery [137].

\section{Endoscopic-assisted catheter placement}

The placement of ventricular shunts in children with complex ventricular anatomy, such as multiloculated hydrocephalus, can be challenging. In such cases, the failure rate of ventriculoperitoneal shunts has been described in up to 35$40 \%$ of patients [138]. Kellnar et al. were the first to pioneer endoscopic-aided catheter placements in 1995, which have since been reproduced successfully for the placement of ventricular catheters and shunts in a wide variety of settings. There is, however, no convincing evidence of reduced shunt failure rates when endoscopic-assisted catheter placement is used.

Table 5 Review of case series for endoscopic placement of ventricular shunts and catheters

\begin{tabular}{|c|c|c|c|c|c|}
\hline Authors & Age range (mean) & Cohort size & Indications & Complications & Results \\
\hline $\begin{array}{l}\text { Kellnar et al. } \\
1995 \text { [139] }\end{array}$ & $\begin{array}{l}\text { Not reported } \\
\quad \text { (pediatric series) }\end{array}$ & 14 & Hydrocephalus & None & $\begin{array}{l}100 \% \text { success rate in catheter } \\
\text { placement; no revision needed } \\
18 \text { months following procedure }\end{array}$ \\
\hline $\begin{array}{l}\text { Villavicencio } \\
\text { et al. } 2003 \\
{[140]}\end{array}$ & $\begin{array}{l}\text { Not reported } \\
\quad \text { (pediatric series) }\end{array}$ & $\begin{array}{l}447(63 \% \\
\text { endoscopically } \\
\text { placed })\end{array}$ & Hydrocephalus & Not reported & $\begin{array}{l}\text { 605/965 total catheters placed were } \\
\text { performed endoscopically; } \\
\text { endoscopy did not independently } \\
\text { improve overall shunt survival }\end{array}$ \\
\hline $\begin{array}{l}\text { Pettorini et al. } \\
2009 \text { [120] }\end{array}$ & $\begin{array}{l}3-75 \text { years } \\
\quad(5 \text { pediatric })\end{array}$ & 8 & $\begin{array}{l}\text { Intracystic catheter } \\
\text { placement for } \\
\text { craniopharygioma }\end{array}$ & $\begin{array}{l}\text { Technical failure due to } \\
\text { extensive dome } \\
\text { calcification }(n=1)\end{array}$ & Hydrocephalus improved in $7 / 8$ patients \\
\hline $\begin{array}{l}\text { Kestle et al. } \\
2003[142]\end{array}$ & $\begin{array}{l}\text { Not reported } \\
\quad(\text { pediatric series) }\end{array}$ & 393 & Hydrocephalus & $\begin{array}{l}\text { Intraoperative bleed }(n=18), \\
\quad \text { shunt infection }(n=44), \\
\text { shunt obstruction }(n=106), \\
\text { loculation }(n=9), \text { over } \\
\text { drainage }(n=14)\end{array}$ & $\begin{array}{l}\text { No difference in first shunt failure } \\
\text { between endoscopically placed vs. } \\
\text { nonendoscopic placed (42 vs. } 34 \% \text { ) }\end{array}$ \\
\hline
\end{tabular}


Technique

Kellnar et al. described the use of a 30-degree optic to visualize the ventricular anatomy and to achieve ideal catheter tip placement anterior of the choroid plexus at the level of the foramen of Monro [139]. Further development of this technique led to the introduction of disposable flexible endoscopes that can be inserted into the ventricular catheter instead of the stylet [140]. The optics and visualization through these disposable endoscopes are, however, limited.

\section{Additional applications}

In addition to the insertion of new catheters for hydrocephalus [140] or for the administration of antineoplastic agents directly to tumor sites [120], endoscopes can be used for the retrieval of failed ventricular catheters. Particularly in the setting of multiloculated hydrocephalus where multiple catheters were placed in the past, retrieval of nonfunctional catheters can be accomplished in an endoscopically assisted manner (Fig. 6). This can be especially important in cases of meningitis and ventriculitis where removal of the potential nidus of infection is of paramount importance [141].

\section{Success rates}

Though increased visualization during catheter insertion via endoscopes holds theoretical promise in improving long-term shunt performance and initially provided promising results, more recent studies suggest such a benefit may not materialize in practice (Table 5). Villavicencio et al. reported no improvement in overall shunt rates at approximately 3 years following endoscopic placement compared to non-endoscopic placement, but they did note decreased odds of failure due to proximal obstruction in the former group. While they found no association with rates of infection, they reported that the odds of a distal malfunction were greater for endoscopically placed shunts, likely explaining the lack of overall benefit [140]. In a separate analysis, Kestle et al. noted a slightly higher rate of shunt failure 1 year following endoscopic placement (42\%) compared to nonendoscopic procedures (34\%), with no statistically significant difference in the time to first failure between both groups [142].

\section{Conclusion}

Over the past few decades, rapid advances in endoscopy have significantly broadened the tools available to the neurosurgeon to treat lesions even in the deepest and most formidable areas of the nervous system. Such neuroendoscopic techniques are now used broadly with proven safety and efficacy in a number of indications, ranging from those in the cranial compartment and skull base to the peripheral nerves and spinal cord. Based on our review, neuroendoscopy in the pediatric population for the treatment of obstructive hydrocephalus, management of intracranial cysts, placement of catheters, biopsy, and resection of intraventricular brain tumors is generally safe and results in good surgical outcomes. Most importantly, appropriate patient selection and critical discussion of treatment indications and success rates remains crucial to maximizing excellent outcomes. While the learning curve for such endoscopic procedures may be steep, the benefit for pediatric patients in the appropriate setting may be equally great.

Acknowledgments We thank Cindy H. Samos for her assistance in preparation of the manuscript.

Conflict of interest The authors report no financial or nonfinancial competing interests to declare.

\section{References}

1. Davis L (1939) Neurological surgery. Lea \& Febinger, Philadelphia, pp 84-102

2. Schultheiss D, Truss MC, Jonas U (1998) History of direct vision internal urethrotomy. Urology 52:729-734

3. Dandy W (1922) Cerebral ventriculoscopy. Bull Johns Hopkins Hosp 33:82-84

4. Perneczky A, Fries G (1998) Endoscope-assisted brain surgery: evolution, basic concept, and current technique. Neurosurgery 42: 219-224

5. Auer LM, Holzer P, Ascher PW, Heppner F (1988) Endoscopic neurosurgery. Acta Neurochir (Wien) 90:1-14

6. Ahmad F, Sandberg DI (2010) Endoscopic management of intraventricular brain tumors in pediatric patients: a review of indications, techniques, and outcomes. J Child Neurol 25:359-367

7. Alaraj A, Lemole MG, Finkle JH, Yudkowsky R, Wallace A, Luciano C, Banerjee PP, Rizzi SH, Charbel FT (2011) Virtual reality training in neurosurgery: review of current status and future applications. Surg Neurol Int 2:52

8. Auer LM, Auer DP (1998) Virtual endoscopy for planning and simulation of minimally invasive neurosurgery. Neurosurgery 43 : 529-537

9. Brown N, Natsupakpong S, Johannsen S, Manjila S, Cai Q, Liberatore V, Cohen AR, Cavusoglu MC (2006) Virtual environment-based training simulator for endoscopic third ventriculostomy. Stud Health Technol Inform 119:73-75

10. Filho FV, Coelho G, Cavalheiro S, Lyra M, Zymberg ST (2011) Quality assessment of a new surgical simulator for neuroendoscopic training. Neurosurg Focus 30:E17

11. Mixter WJ (1923) Ventriculostomy and puncture of the floor of the third ventricle. Boston Med Surg J 188:277-278

12. Di Rocco C, Cinalli G, Massimi L, Spennato P, Cianciulli E, Tamburrini G (2006) Endoscopic third ventriculostomy in the treatment of hydrocephalus in pediatric patients. Adv Tech Stand Neurosurg 31:119-219

13. Enchev Y, Oi S (2008) Historical trends of neuroendoscopic surgical techniques in the treatment of hydrocephalus. Neurosurg Rev 31:249-262

14. Warf BC (2005) Comparison of endoscopic third ventriculostomy alone and combined with choroid plexus cauterization in infants 
younger than 1 year of age: a prospective study in 550 African children. J Neurosurg 103:475-481

15. Warf BC, Campbell JW (2008) Combined endoscopic third ventriculostomy and choroid plexus cauterization as primary treatment of hydrocephalus for infants with myelomeningocele: longterm results of a prospective intent-to-treat study in 115 East African infants. J Neurosurg Pediatr 2:310-316

16. Koch-Wiewrodt D, Wagner W (2006) Success and failure of endoscopic third ventriculostomy in young infants: are there different age distributions? Childs Nerv Syst 22:1537-1541

17. Warf BC (2013) Congenital idiopathic hydrocephalus of infancy: the results of treatment by endoscopic third ventriculostomy with or without choroid plexus cauterization and suggestions for how it works. Childs Nerv Syst 29:935-940

18. Al-Tamimi YZ, Bhargava D, Surash S, Ramirez RE, Novegno F, Crimmins DW, Tyagi AK, Chumas PD (2008) Endoscopic biopsy during third ventriculostomy in paediatric pineal region tumours. Childs Nerv Syst 24:1323-1326

19. Pople IK, Athanasiou TC, Sandeman DR, Coakham HB (2001) The role of endoscopic biopsy and third ventriculostomy in the management of pineal region tumours. Br J Neurosurg 15:305-311

20. Pople IK, Edwards RJ, Aquilina K (2001) Endoscopic methods of hydrocephalus treatment. Neurosurg Clin N Am 12:719-735

21. Wellons JC 3rd, Tubbs RS, Banks JT, Grabb B, Blount JP, Oakes WJ, Grabb PA (2002) Long-term control of hydrocephalus via endoscopic third ventriculostomy in children with tectal plate gliomas. Neurosurgery 51:63-67

22. King JA, Auguste KI, Halliday W, Drake JM, Kulkarni AV (2010) Ventriculocystostomy and endoscopic third ventriculostomy/shunt placement in the management of hydrocephalus secondary to giant retrocerebellar cysts in infancy. J Neurosurg Pediatr 5:403-407

23. Bhatia R, Tahir M, Chandler CL (2009) The management of hydrocephalus in children with posterior fossa tumours: the role of preresectional endoscopic third ventriculostomy. Pediatr Neurosurg 45: 186-191

24. Sainte-Rose C, Cinalli G, Roux FE, Maixner R, Chumas PD, Mansour M, Carpentier A, Bourgeois M, Zerah M, Pierre-Kahn A, Renier D (2001) Management of hydrocephalus in pediatric patients with posterior fossa tumors: the role of endoscopic third ventriculostomy. J Neurosurg 95:791-797

25. de Oliveira RS, Barbosa A, Vicente YA, Machado HR (2007) An alternative approach for management of abdominal cerebrospinal fluid pseudocysts in children. Childs Nerv Syst 23:85-90

26. Elgamal EA (2010) Continuous monitoring of intracranial pressure after endoscopic third ventriculostomy in the management of CSF shunt failure. Minim Inv Neurosurg 53:49-54

27. Chernov MF, Kamikawa S, Yamane F, Ishihara S, Hori T (2005) Neurofiberscope-guided management of slit-ventricle syndrome due to shunt placement. J Neurosurg 102:260-267

28. Sandberg DI (2008) Endoscopic management of hydrocephalus in pediatric patients: a review of indications, techniques, and outcomes. J Child Neurol 23:550-560

29. Guzman R, Pendharkar AV, Zerah M, Sainte-Rose C (2013) Use of the NeuroBalloon catheter for endoscopic third ventriculostomy. J Neurosurg Pediatr 11:302-306

30. Kulkarni AV, Drake JM, Kestle JR, Mallucci CL, Sgouros S, Constantini S, Canadian Pediatric Neurosurgery Study G (2010) Predicting who will benefit from endoscopic third ventriculostomy compared with shunt insertion in childhood hydrocephalus using the ETV Success Score. J Neurosurg Pediatr 6:310-315

31. Kulkarni AV, Drake JM, Mallucci CL, Sgouros S, Roth J, Constantini S, Canadian Pediatric Neurosurgery Study G (2009) Endoscopic third ventriculostomy in the treatment of childhood hydrocephalus. J Pediatr 155:254-259

32. Peretta P, Cinalli G, Spennato P, Ragazzi P, Ruggiero C, Aliberti F, Carlino C, Cianciulli E (2009) Long-term results of a second endoscopic third ventriculostomy in children: retrospective analysis of 40 cases. Neurosurgery 65:539-547

33. Ogiwara H, Dipatri AJ Jr, Alden TD, Bowman RM, Tomita T (2010) Endoscopic third ventriculostomy for obstructive hydrocephalus in children younger than 6 months of age. Childs Nerv Syst 26:343-347

34. Wagner W, Koch D (2005) Mechanisms of failure after endoscopic third ventriculostomy in young infants. J Neurosurg 103:43-49

35. Egger D, Balmer B, Altermatt S, Meuli M (2010) Third ventriculostomy in a single pediatric surgical unit. Childs Nerv Syst 26:93-99

36. Elgamal EA, El-Dawlatly AA, Murshid WR, El-Watidy SM, Jamjoom ZA (2011) Endoscopic third ventriculostomy for hydrocephalus in children younger than 1 year of age. Childs Nerv Syst 27:111-116

37. Sufianov AA, Sufianova GZ, Iakimov IA (2010) Endoscopic third ventriculostomy in patients younger than 2 years: outcome analysis of 41 hydrocephalus cases. J Neurosurg Pediatr 5:392-401

38. Warf BC, Kulkarni AV (2010) Intraoperative assessment of cerebral aqueduct patency and cisternal scarring: impact on success of endoscopic third ventriculostomy in 403 African children. J Neurosurg Pediatr 5:204-209

39. Warf BC (2013) The impact of combined endoscopic third ventriculostomy and choroid plexus cauterization on the management of pediatric hydrocephalus in developing countries. World Neurosurg 79(S23):e13-e25

40. Schwartz TH, Ho B, Prestigiacomo CJ, Bruce JN, Feldstein NA, Goodman RR (1999) Ventricular volume following third ventriculostomy. J Neurosurg 91:20-25

41. Pindrik J, Jallo GI, Ahn ES (2013) Changes in third ventricular size in pediatric patients undergoing endoscopic third ventriculostomy. Childs Nerv Syst 29:2027-2034

42. St George E, Natarajan K, Sgouros S (2004) Changes in ventricular volume in hydrocephalic children following successful endoscopic third ventriculostomy. Childs Nerv Syst 20:834-838

43. Di Rocco F, Grevent D, Drake JM, Boddaert N, Puget S, Roujeau T, Blauwblomme T, Zerah M, Brunelle F, Sainte-Rose C (2012) Changes in intracranial CSF distribution after ETV. Childs Nerv Syst 28:997-1002

44. Garg AK, Suri A, Sharma BS, Shamim SA, Bal CS (2009) Changes in cerebral perfusion hormone profile and cerebrospinal fluid flow across the third ventriculostomy after endoscopic third ventriculostomy in patients with aqueductal stenosis: a prospective study. Clinical article. J Neurosurg Pediatr 3:29-36

45. Drake JM, Kulkarni AV, Kestle J (2009) Endoscopic third ventriculostomy versus ventriculoperitoneal shunt in pediatric patients: a decision analysis. Childs Nerv Syst 25:467-472

46. Kulkarni AV, Shams I, Cochrane DD, McNeely PD (2010) Quality of life after endoscopic third ventriculostomy and cerebrospinal fluid shunting: an adjusted multivariable analysis in a large cohort. J Neurosurg Pediatr 6:11-16

47. Teo C, Rahman S, Boop FA, Cherny B (1996) Complications of endoscopic neurosurgery. Childs Nerv Syst 12:248-253

48. Cinalli G, Spennato P, Ruggiero C, Aliberti F, Trischitta V, Buonocore MC, Cianciulli E, Maggi G (2007) Complications following endoscopic intracranial procedures in children. Childs Nerv Syst 23:633-644

49. Peretta P, Ragazzi P, Galarza M, Genitori L, Giordano F, Mussa F, Cinalli G (2006) Complications and pitfalls of neuroendoscopic surgery in children. J Neurosurg 105:187-193

50. Freudenstein D, Wagner A, Ernemann U, Duffner F (2002) Subdural hygroma as a complication of endoscopic neurosurgery - two case reports. Neurol Med Chir (Tokyo) 42:554-559

51. Macarthur DC, Buxton N, Vloeberghs M, Punt J (2001) The effectiveness of neuroendoscopic interventions in children with brain tumours. Childs Nerv Syst 17:589-594 
52. Drake JM, Riva-Cambrin J, Jea A, Auguste K, Tamber M, LambertiPasculli M (2010) Prospective surveillance of complications in a pediatric neurosurgery unit. J Neurosurg Pediatr 5:544-548

53. Fritsch MJ, Bauer M, Partsch CJ, Sippell WG, Mehdorn HM (2007) Endocrine evaluation after endoscopic third ventriculostomy (ETV) in children. Childs Nerv Syst 23:627-631

54. Aldana PR, Kestle JR, Brockmeyer DL, Walker ML (2003) Results of endoscopic septal fenestration in the treatment of isolated ventricular hydrocephalus. Pediatr Neurosurg 38:286-294

55. Souweidane MM (2005) Endoscopic management of pediatric brain tumors. Neurosurg Focus 18:E1

56. Putnam T (1934) Treatment of hydrocephalus by endoscopic coagulation of the choroid plexus. N Eng J Med 210:1373-1376

57. Scarff JE (1970) The treatment of nonobstructive (communicating) hydrocephalus by endoscopic cauterization of the choroid plexuses. J Neurosurg 33:1-18

58. Pople IK, Ettles D (1995) The role of endoscopic choroid plexus coagulation in the management of hydrocephalus. Neurosurgery 36 : 698-701

59. Warf BC, Tracy S, Mugamba J (2012) Long-term outcome for endoscopic third ventriculostomy alone or in combination with choroid plexus cauterization for congenital aqueductal stenosis in African infants. J Neurosurg Pediatr 10:108-111

60. Chamiraju P, Bhatia S, Sandberg DI, Ragheb J (2014) Endoscopic third ventriculostomy and choroid plexus cauterization in posthemorrhagic hydrocephalus of prematurity. J Neurosurg Pediatr e7

61. Warf BC, Campbell JW, Riddle E (2011) Initial experience with combined endoscopic third ventriculostomy and choroid plexus cauterization for post-hemorrhagic hydrocephalus of prematurity: the importance of prepontine cistern status and the predictive value of FIESTA MRI imaging. Childs Nerv Syst 27:1063-1071

62. Jodicke A, Accomazzi V, Reiss I, Boker DK (2003) Virtual endoscopy of the cerebral ventricles based on 3-D ultrasonography. Ultrasound Med Biol 29:339-345

63. Sangra M, Clark S, Hayhurst C, Mallucci C (2009) Electromagnetic-guided neuroendoscopy in the pediatric population. J Neurosurg Pediatr 3:325-330

64. Schroeder HW, Nehlsen M (2009) Value of high-definition imaging in neuroendoscopy. Neurosurg Rev 32:303-308

65. Drake JM (2008) The surgical management of pediatric hydrocephalus. Neurosurgery 62(Suppl 2):633-640

66. Lipina R, Reguli S, Novackova L, Podesvova H, Brichtova E (2010) Relation between TGF-beta 1 levels in cerebrospinal fluid and ETV outcome in premature newborns with posthemorrhagic hydrocephalus. Childs Nerv Syst 26:333-341

67. Tubbs RS, Loukas M, Shoja MM, Wellons JC, Cohen-Gadol AA (2009) Feasibility of ventricular expansion postmortem: a novel laboratory model for neurosurgical training that simulates intraventricular endoscopic surgery. J Neurosurg 111:1165-1167

68. Badie B, Brooks N, Souweidane MM (2004) Endoscopic and minimally invasive microsurgical approaches for treating brain tumor patients. J Neurooncol 69:209-219

69. Heilman CB, Cohen AR (1991) Endoscopic ventricular fenestration using a "saline torch". J Neurosurg 74:224-229

70. Oi S, Hidaka M, Honda Y, Togo K, Shinoda M, Shimoda M, Tsugane R, Sato O (1999) Neuroendoscopic surgery for specific forms of hydrocephalus. Childs Nerv Syst 15:56-68

71. Oertel JM, Baldauf J, Schroeder HW, Gaab MR (2009) Endoscopic options in children: experience with 134 procedures. J Neurosurg Pediatr 3:81-89

72. Greenfield JP, Souweidane MM (2005) Endoscopic management of intracranial cysts. Neurosurg Focus 19:E7

73. Rengachary SS, Watanabe I, Brackett CE (1978) Pathogenesis of intracranial arachnoid cysts. Surg Neurol 9:139-144

74. Harsh GRT, Edwards MS, Wilson CB (1986) Intracranial arachnoid cysts in children. J Neurosurg 64:835-842
75. Ersahin Y, Kesikci H, Ruksen M, Aydin C, Mutluer S (2008) Endoscopic treatment of suprasellar arachnoid cysts. Childs Nerv Syst 24:1013-1020

76. Al-Holou WN, Yew AY, Boomsaad ZE, Garton HJ, Muraszko KM, Maher CO (2010) Prevalence and natural history of arachnoid cysts in children. J Neurosurg Pediatr 5:578-585

77. Parsch CS, Krauss J, Hofmann E, Meixensberger J, Roosen K (1997) Arachnoid cysts associated with subdural hematomas and hygromas: analysis of 16 cases, long-term follow-up, and review of the literature. Neurosurgery 40:483-490

78. Pradilla G, Jallo G (2007) Arachnoid cysts: case series and review of the literature. Neurosurg Focus 22:E7

79. Spacca B, Kandasamy J, Mallucci CL, Genitori L (2010) Endoscopic treatment of middle fossa arachnoid cysts: a series of 40 patients treated endoscopically in two centres. Childs Nerv Syst 6:163-172

80. Kim MH, Jho HD (2010) Endoscopic management of cranial arachnoid cysts using extra-channel method. J Korean Neurosurg Soc 47: 433-436

81. Ciricillo SF, Cogen PH, Harsh GR, Edwards MS (1991) Intracranial arachnoid cysts in children. A comparison of the effects of fenestration and shunting. J Neurosurg 74:230-235

82. Di Rocco C (2010) Sylvian fissure arachnoid cysts: we do operate on them but should it be done? Childs Nerv Syst 26:173-175

83. Hund-Georgiadis M, Yves Von Cramon D, Kruggel F, Preul C (2002) Do quiescent arachnoid cysts alter CNS functional organization?: a fMRI and morphometric study. Neurology 59:1935-1939

84. Sgouros S, Chapman S (2001) Congenital middle fossa arachnoid cysts may cause global brain ischaemia: a study with $99 \mathrm{Tc}$ hexamethylpropyleneamineoxime single photon emission computerised tomography scans. Pediatr Neurosurg 35:188-194

85. Tsutsumi S, Kondo A, Yasumoto Y, Ito M (2008) Asymptomatic huge congenital arachnoid cyst successfully treated by endoscopic surgery - case report. Neurol Med Chir (Tokyo) 48:405-408

86. Wester K, Helland CA (2008) How often do chronic extra-cerebral haematomas occur in patients with intracranial arachnoid cysts? J Neurol Neurosurg Psychiatry 79:72-75

87. Cinalli G, Spennato P, Columbano L, Ruggiero C, Aliberti F, Trischitta V, Buonocore MC, Cianciulli E (2010) Neuroendoscopic treatment of arachnoid cysts of the quadrigeminal cistern: a series of 14 cases. J Neurosurg Pediatr 6:489-497

88. Abbott R (2004) The endoscopic management of arachnoidal cysts. Neurosurg Clin N Am 15:9-17

89. El-Ghandour NM (2012) Endoscopic treatment of middle cranial fossa arachnoid cysts in children. J Neurosurg Pediatr 9:231-238

90. Almeida JP, Quinino S, Faquini IV, Silva DO, Albuquerque LA, Mendes JC, Azevedo-Filho H (2008) Neuroendoscopic treatment of quadrigeminal arachnoid cyst in a two-year-old child. Arq Neuropsiquitr 66:758-760

91. Gangemi M, Colella G, Magro F, Maiuri F (2007) Suprasellar arachnoid cysts: endoscopy versus microsurgical cyst excision and shunting. Br J Neurosurg 21:276-280

92. Golash A, Mitchell G, Mallucci C, May P, Pilling D (2001) Prenatal diagnosis of suprasellar arachnoid cyst and postnatal endoscopic treatment. Childs Nerv Syst 17:739-742

93. Kirollos RW, Javadpour M, May P, Mallucci C (2001) Endoscopic treatment of suprasellar and third ventricle-related arachnoid cysts. Childs Nerv Syst 17:713-718

94. Van Beijnum J, Hanlo PW, Han KS, Ludo Van der Pol W, Verdaasdonk RM, Van Nieuwenhuizen O (2006) Navigated laser-assisted endoscopic fenestration of a suprasellar arachnoid cyst in a 2-year-old child with bobble-head doll syndrome. J Neurosurg 104:348-351

95. Fitzpatrick MO, Barlow P (2001) Endoscopic treatment of prepontine arachnoid cysts. Br J Neurosurg 15:234-238

96. Cinalli G, Peretta P, Spennato P, Savarese L, Varone A, Vedova P, Grimaldi G, Ragazzi P, Ruggiero C, Cianciulli E, Maggi G (2006) 
Neuroendoscopic management of interhemispheric cysts in children. J Neurosurg 105:194-202

97. Dwarakanath S, Suri A, Mahapatra AK, Mehta VS, Gaikwad S, Sarkar C (2006) Endoscopic assisted excision of a retroclival arachnoid cyst presenting as hysterical breathlessness. Childs Nerv Syst 22:424-427

98. Di Rocco FSRJ, Roujeau T, Puget S, Sainte-Rose C, Zerah M (2010) Limits of endoscopic treatment of sylvian arachnoid cysts in children. Childs Nerv Syst 26:155-162

99. Lewis AI, Keiper GL Jr, Crone KR (1995) Endoscopic treatment of loculated hydrocephalus. J Neurosurg 82:780-785

100. Charalampaki P, Filippi R, Welschehold S, Conrad J (2005) Endoscopic and endoscope-assisted neurosurgical treatment of suprasellar arachnoidal cysts (Mickey Mouse cysts). Minim Inv Neurosurg 48:283-288

101. Maher CO, Goumnerova L (2011) The effectiveness of ventriculocystocisternostomy for suprasellar arachnoid cysts. J Neurosurg Pediatr 7:64-72

102. Rizk E, Chern JJ, Tagayun C, Tubbs RS, Hankinson T, Rozzelle C, Oakes WJ, Blount JP, Wellons JC (2013) Institutional experience of endoscopic suprasellar arachnoid cyst fenestration. Childs Nerv Syst 29:1345-1347

103. Tirakotai W, Schulte DM, Bauer BL, Bertalanffy H, Hellwig D (2004) Neuroendoscopic surgery of intracranial cysts in adults. Childs Nerv Syst 20:842-851

104. Hellwig D, Bauer BL, Schulte M, Gatscher S, Riegel T, Bertalanffy $\mathrm{H}$ (2003) Neuroendoscopic treatment for colloid cysts of the third ventricle: the experience of a decade. Neurosurgery 52:525-533

105. Margetis K, Souweidane MM (2013) Endoscopic treatment of intraventricular cystic tumors. World Neurosurg 79:e11

106. Lewis AI, Crone KR, Taha J, van Loveren HR, Yeh HS, Tew JM Jr (1994) Surgical resection of third ventricle colloid cysts. Preliminary results comparing transcallosal microsurgery with endoscopy. J Neurosurg 81:174-178

107. Decq P, Le Guerinel C, Brugieres P, Djindjian M, Silva D, Keravel Y, Melon E, Nguyen JP (1998) Endoscopic management of colloid cysts. Neurosurgery 42:1288-1294

108. Deinsberger W, Boker DK, Bothe HW, Samii M (1994) Stereotactic endoscopic treatment of colloid cysts of the third ventricle. Acta Neurochir (Wien) 131:260-264

109. Kehler U, Brunori A, Gliemroth J, Nowak G, Delitala A, Chiappetta F, Arnold H (2001) Twenty colloid cysts - comparison of endoscopic and microsurgical management. Minim Inv Neurosurg 44:121-127

110. King WA, Ullman JS, Frazee JG, Post KD, Bergsneider M (1999) Endoscopic resection of colloid cysts: surgical considerations using the rigid endoscope. Neurosurgery 44:1103-1109

111. Powell MP, Torrens MJ, Thomson JL, Horgan JG (1983) Isodense colloid cysts of the third ventricle: a diagnostic and therapeutic problem resolved by ventriculoscopy. Neurosurgery 13:234-237

112. Maqsood AA, Devi IB, Mohanty A, Chandramouli BA, Sastry KV (2006) Third ventricular colloid cysts in children. Pediatr Neurosurg 42:147-150

113. Teo C (1999) Complete endoscopic removal of colloid cysts: issues of safety and efficacy. Neurosurg Focus 6:e9

114. Charalampaki P, Filippi R, Welschehold S, Perneczky A (2006) Endoscope-assisted removal of colloid cysts of the third ventricle. Neurosurg Rev 29:72-79

115. Barajas MA, Ramirez-Guzman G, Rodriguez-Vazquez C, ToledoBuenrostro V, Velasquez-Santana H, del Robles RV, CuevasSolorzano A, Rodriguez-Hernandez G (2002) Multimodal management of craniopharyngiomas: neuroendoscopy, microsurgery, and radiosurgery. J Neurosurg 97:607-609

116. Fischer EG, Welch K, Shillito J Jr, Winston KR, Tarbell NJ (1990) Craniopharyngiomas in children. Long-term effects of conservative surgical procedures combined with radiation therapy. J Neurosurg 73:534-540
117. Puget $S$ (2012) Treatment strategies in childhood craniopharyngioma. Front Endocrinol (Lausanne) 3:64

118. Sainte-Rose C, Puget S, Wray A, Zerah M, Grill J, Brauner R, Boddaert N, Pierre-Kahn A (2005) Craniopharyngioma: the pendulum of surgical management. Childs Nerv Syst 21:691-695

119. Muller HL, Albanese A, Calaminus G, Hargrave D, Garre ML, Gebhardt U, Saran F, Sorensen N, Spoudeas HA (2006) Consensus and perspectives on treatment strategies in childhood craniopharyngioma: results of a meeting of the Craniopharyngioma Study Group (SIOP), Genova, 2004. J Pediatr Endocrin 19(Suppl 1):453-454

120. Pettorini BL, Tamburrini G, Massimi L, Caldarelli M, Di Rocco C (2009) Endoscopic transventricular positioning of intracystic catheter for treatment of craniopharyngioma. J Neurosurg Pediatr 4: 245-248

121. Joki T, Oi S, Babapour B, Kaito N, Ohashi K, Ebara M, Kato M, Abe T (2002) Neuroendoscopic placement of Ommaya reservoir into a cystic craniopharyngioma. Childs Nerv Syst 18:629-633

122. Mori R, Joki T, Nonaka Y, Ikeuchi S, Abe T (2013) Parallel insertion endoscopic technique for precise catheter placement in cystic craniopharyngiomas. J Neurol Surg A Cent Eur Neurosurg (epub)

123. Caceres A (2005) Intracavitary therapeutic options in the management of cystic craniopharyngioma. Childs Nerv Syst 21:705-718

124. Fukushima T (1978) Endoscopic biopsy of intraventricular tumors with the use of a ventriculofiberscope. Neurosurgery 2:110-113

125. Gaab MR (2013) Instrumentation: endoscopes and equipment. World Neurosurg 79:e11-e21

126. Roth J, Bercu MM, Constantini S (2013) Combined open microsurgical and endoscopic resection of hypothalamic hamartomas. J Neurosurg Pediatr 11:491-494

127. Carr K, Zuckerman SL, Tomycz L, Pearson MM (2013) Endoscopic removal of an intraventricular primitive neuroectodermal tumor: retrieval of a free-floating fragment using a urological basket retriever. J Neurosurg Pediatr 12:25-29

128. Gore PA, Nakaji P, Deshmukh V, Rekate HL (2006) Synchronous endoscopy and microsurgery: a novel strategy to approach complex ventricular lesions. Report of three cases. J Neurosurg 105:485-489

129. Gaab MR, Schroeder HW (1999) Neuroendoscopic approach to intraventricular lesions. Neurosurg Focus 6:e5

130. Yamamoto M, Oka K, Takasugi S, Hachisuka S, Miyake E, Tomonaga M (1997) Flexible neuroendoscopy for percutaneous treatment of intraventricular lesions in the absence of hydrocephalus. Minim Inv Neurosurg 40:139-143

131. Macarthur DC, Buxton N, Punt J, Vloeberghs M, Robertson IJ (2002) The role of neuroendoscopy in the management of brain tumours. Br J Neurosurg 16:465-470

132. Ferrer E, Santamarta D, Garcia-Fructuoso G, Caral L, Rumia J (1997) Neuroendoscopic management of pineal region tumours. Acta Neurochir (Wien) 139:12-20

133. Luther N, Cohen A, Souweidane MM (2005) Hemorrhagic sequelae from intracranial neuroendoscopic procedures for intraventricular tumors. Neurosurg Focus 19:E9

134. Constantini S, Mohanty A, Zymberg S, Cavalheiro S, Mallucci C, Hellwig D, Ersahin Y, Mori H, Mascari C, Val JA, Wagner W, Kulkarni AV, Sgouros S, Oi S (2013) Safety and diagnostic accuracy of neuroendoscopic biopsies: an international multicenter study. J Neurosurg Pediatr 11:704-709

135. Fiorindi A, Longatti P (2008) A restricted neuroendoscopic approach for pathological diagnosis of intraventricular and paraventricular tumours. Acta Neurochir (Wien) 150:1235-1239

136. Kim K, Yeon JY, Seol HJ, Shin HJ (2013) Transventricular endoscopic biopsy of suprasellar tumors: a pediatric case series. Childs Nerv Syst 29:1285-1291

137. Souweidane MM (2005) Endoscopic surgery for intraventricular brain tumors in patients without hydrocephalus. Neurosurgery 57 : 312-318 
138. Drake JM, Kestle JR, Milner R, Cinalli G, Boop F, Piatt J Jr, Haines S, Schiff SJ, Cochrane DD, Steinbok P, MacNeil N (1998) Randomized trial of cerebrospinal fluid shunt valve design in pediatric hydrocephalus. Neurosurgery 43:294-303

139. Kellnar S, Boehm R, Ring E (1995) Ventriculoscopy-aided implantation of ventricular shunts in patients with hydrocephalus. J Pediatr Surg 30:1450-1451

140. Villavicencio AT, Leveque JC, McGirt MJ, Hopkins JS, Fuchs HE, George TM (2003) Comparison of revision rates following endoscopically versus nonendoscopically placed ventricular shunt catheters. Surg Neurol 59:375-379

141. Pettorini BL, Frassanito P, Tamburrini G, Massimi L, Caldarelli M, Di Rocco C (2008) Retrieval of ventricular catheter with the aid of endoscopy: technical note. J Neurosurg Pediatr 2:71-74

142. Kestle JR, Drake JM, Cochrane DD, Milner R, Walker ML, Abbott R 3rd, Boop FA, Endoscopic Shunt Insertion Trial p (2003) Lack of benefit of endoscopic ventriculoperitoneal shunt insertion: a multicenter randomized trial. J Neurosurg 98:284-290

143. Di Rocco F, Juca CE, Arnaud E, Renier D, Sainte-Rose C (2010) The role of endoscopic third ventriculostomy in the treatment of hydrocephalus associated with faciocraniosynostosis. J Neurosurg Pediatr 6:17-22

144. Marton E, Feletti A, Basaldella L, Longatti P (2010) Endoscopic third ventriculostomy in previously shunted children: a retrospective study. Childs Nerv Syst 26:937-943

145. Tamburrini G, Pettorini BL, Massimi L, Caldarelli M, Di Rocco C (2008) Endoscopic third ventriculostomy: the best option in the treatment of persistent hydrocephalus after posterior cranial fossa tumour removal? Childs Nerv Syst 24:1405-1412

146. Choi JU, Kim DS, Huh R (1999) Endoscopic approach to arachnoid cyst. Childs Nerv Syst 15:285-291

147. Karabatsou K, Hayhurst C, Buxton N, O'Brien DF, Mallucci CL (2007) Endoscopic management of arachnoid cysts: an advancing technique. J Neurosurg 106:455-462

148. Hopf NJ, Perneczky A (1998) Endoscopic neurosurgery and endoscope-assisted microneurosurgery for the treatment of intracranial cysts. Neurosurgery 43:1330-1336
149. Schroeder HW, Gaab MR, Niendorf WR (1996) Neuroendoscopic approach to arachnoid cysts. J Neurosurg 85:293-298

150. Yadav YR, Parihar V, Sinha M, Jain N (2010) Endoscopic treatment of the suprasellar arachnoid cyst. Neurol India 58:280-283

151. Shim KW, Lee YH, Park EK, Park YS, Choi JU, Kim DS (2009) Treatment option for arachnoid cysts. Childs Nerv Syst 25:1459-1466

152. Ersahin Y, Kesikci H (2009) Endoscopic management of quadrigeminal arachnoid cysts. Childs Nerv Syst 25:569-576

153. Nowoslawska E, Polis L, Kaniewska D, Mikolajczyk W, Krawczyk J, Szymanski W, Zakrzewski K, Podciechowska J, Polis B (2006) Neuroendoscopic techniques in the treatment of arachnoid cysts in children and comparison with other operative methods. Childs Nerv Syst 22:599-604

154. El-Ghandour NM (2008) Endoscopic cyst fenestration in the treatment of multiloculated hydrocephalus in children. J Neurosurg Pediatr 1:217-222

155. Delitala A, Brunori A, Chiappetta F (2004) Purely neuroendoscopic transventricular management of cystic craniopharyngiomas. Childs Nerv Syst 20:858-862

156. Nakahara Y, Koga H, Maeda K, Takagi M, Tabuchi K (2004) Neuroendoscopic transventricular surgery for suprasellar cystic mass lesions such as cystic craniopharyngioma and Rathke cleft cyst. Neurol Med Chir (Tokyo) 44:408-413

157. Gangemi M, Maiuri F, Colella G, Sardo L (1999) Endoscopic surgery for intracranial cerebrospinal fluid cyst malformations. Neurosurg Focus 6:e6

158. Ahn ES, Goumnerova L (2010) Endoscopic biopsy of brain tumors in children: diagnostic success and utility in guiding treatment strategies. J Neurosurg Pediatr 5:255-262

159. Song JH, Kong DS, Shin HJ (2010) Feasibility of neuroendoscopic biopsy of pediatric brain tumors. Childs Nerv Syst 26:1593-1598

160. Depreitere B, Dasi N, Rutka J, Dirks P, Drake J (2007) Endoscopic biopsy for intraventricular tumors in children. J Neurosurg 106: 340-346

161. Yamini B, Refai D, Rubin CM, Frim DM (2004) Initial endoscopic management of pineal region tumors and associated hydrocephalus: clinical series and literature review. J Neurosurg 100:437-441 